Original Research Paper

\title{
A Contribution of the CDP Gathers and Pre-Stack Seismic Inversion in the Prospect Evaluation: A Case Study of EI Mansoura Field, Nile Delta, Egypt
}

\author{
${ }^{1}$ Mohamed Hussein, ${ }^{2}$ Ahmed Abu El-Ata and ${ }^{3}$ Mohamed El-Behiry \\ ${ }^{I}$ Department of Petroleum Engineering, Future University (FUE), Cairo, Egypt \\ ${ }^{2}$ Department of Geophysics, Ain Shams University, Cairo, Egypt \\ ${ }^{3}$ Department of Geophysics, Cairo University, Cairo, Egypt
}

\author{
Article history \\ Received: 18-04-2019 \\ Revised: 19-05-2019 \\ Accepted: 16-07-2019 \\ Corresponding Author: \\ Mohamed Hussein \\ Department of Petroleum \\ Engineering, Future University \\ (FUE), Cairo, Egypt \\ Email: hessein8@hotmail.com
}

\begin{abstract}
This case study showing the usefulness of the Common Depth Point (CDP's) analysis to assess the amplitude response which is similar at two cases (gas-bearing and dry sands) after stack, using the Amplitude Versus Offset (AVO) analysis and the pre-stack inversion to understand the reservoir configuration and its relationship to the different amplitude response. The results led to a high success of exploration ratio as the positives vastly outweigh the negatives. Several lessons have been learned, which how to differentiate between the similar amplitude responses for two dry and gas discovery wells-by understanding the relationship between the near traces (near offset) and the far traces (far offset) from the CDP gathers in order to reduce the amplitude anomalies to their right justification. Consequently, a variation in the reflectivity strength is observed, which is controlled by the mechanical properties of the rocks: compression wave (VP), shear wave (Vs) and density. These properties are affected by litho logy and fluid contents. The analysis of the CDP's gathers and the inversion results help in validating the prospects before drilling and in determining the response of the seismic amplitude deviation with the offset, so it is possible to confirm the amplitude anomaly if it is related to hydrocarbon or not.
\end{abstract}

Keywords: CDP Gathers, AVO Analysis, Seismic Inversion, Compression Wave, Shear Wave

\section{Introduction}

The Nile Delta region discovered gas reserves reach to about 58 Tcf until now (Nini et al., 2010), from different stratigraphic levels, ranging from the Oligocene to the Plio-Pleistocene, it is consequently considered the greatest prolific region for production of gas in Egypt. So, many international companies entering the race to take great areas to make full studies and applying new techniques to investigate new potential reservoirs to get more hydrocarbons. The seismic response is affected by the physical properties of the pore fluids in a porous rock containing those fluids (Cardamone et al., 2007). In the last decade, seismic AVO and inversion analysis have become prominent in the Direct Hydrocarbons Indicator (DHI's) aimed at characterizing the fluid content or the lithology of a possible reservoir and reducing the exploration drilling risk. The AVO method measures the differences in seismic amplitude with offset. In the present day, the AVO modeling is broadly used in detection of hydrocarbon, lithology determination and fluid analysis, according to the fact that seismic amplitude is affected by the physical properties changes above and below the boundaries. After the quantitative seismic interpretation for the different stratigraphic levels in the concerned area and application of the AVO detailed study, it is observed that, same amplitude response has occurred in both two drilled wells gas- 
bearing and dry sands in the stacked seismic sections. The aim of this research is to understand the reasons of the amplitude response which is similar at two cases, using advanced seismic applications, such as AVO analysis and pre-stack inversion.

\section{Study Area}

The study area is one of the most promising areas for gas and oil, approximately $130 \mathrm{~km}$ NNE of Cairo and considered a part of the unstable shelf structural regime of the Nile Delta basin (Fig. 1). The potentiality of the Nile Delta is thought to be restricted to the Neogene-Quaternary sequence (EGPC, 1994; Abdel, 2001). The Neogene-Quaternary sequence is separated to main three sedimentary successions: Miocene, Pliocene and Holocene (Said, 1962; Ross and Uchupi, 1977; Rizzini et al., 1978; Kamel et al., 1998). The successions are dominated by sandstones and shales, overlie on a pre-Miocene sequence, which deep down to the Jurassic (Fig. 2).
At El Mansoura area, the Neogene sequence consists of the Messinian sand and shale of Qawasim Formation, which are unconformable covered by the shales of Pliocene with slight sand of Kafr El Sheikh and El Wastani Formations. Above all of these, there are claystones of Mit Ghamr and Pleistocene sands. In the concerned area, many wells have been drilled targeting the Messinian section, where clear AVO classes II and III anomalies indicate the presence of gas-bearing sands within the Abu Madi Formation Fig. 3. Highlights two striking seismic amplitude anomalies, located in two different locations but have the same amplitude response. After drilling both anomalies, it has been found, that the first well (to the left of Fig. 3) was gas-bearing sand and the other one (to the right of Fig. 3) was dry sand. So, why is there a difference in the results of the two wells? This question cannot be answered before analysis of the CDP gathers and studying the AVO response at the two locations, to avoid any further dry wells in the future exploration and development for other fields.

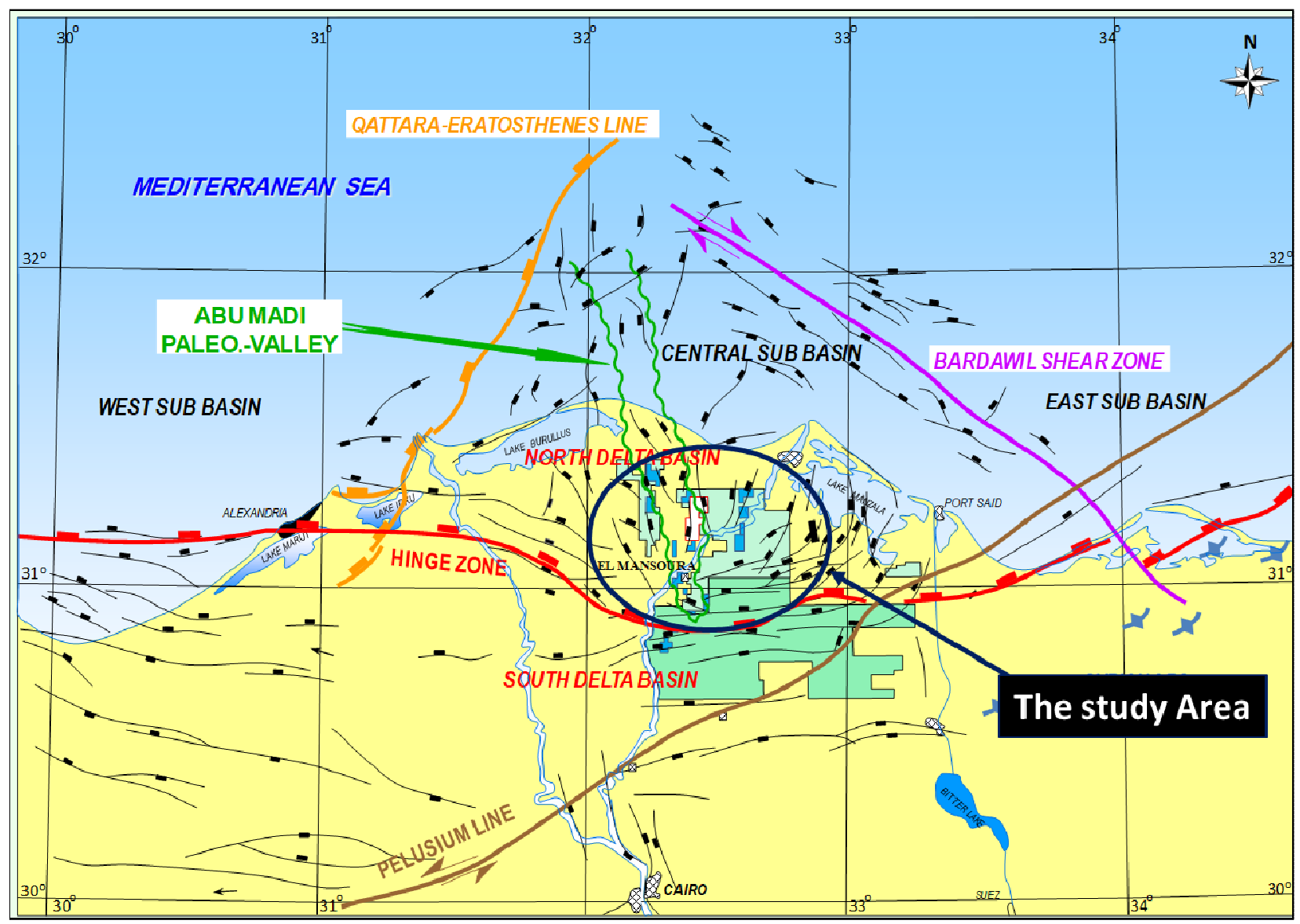

Fig. 1: Location map of the study area 


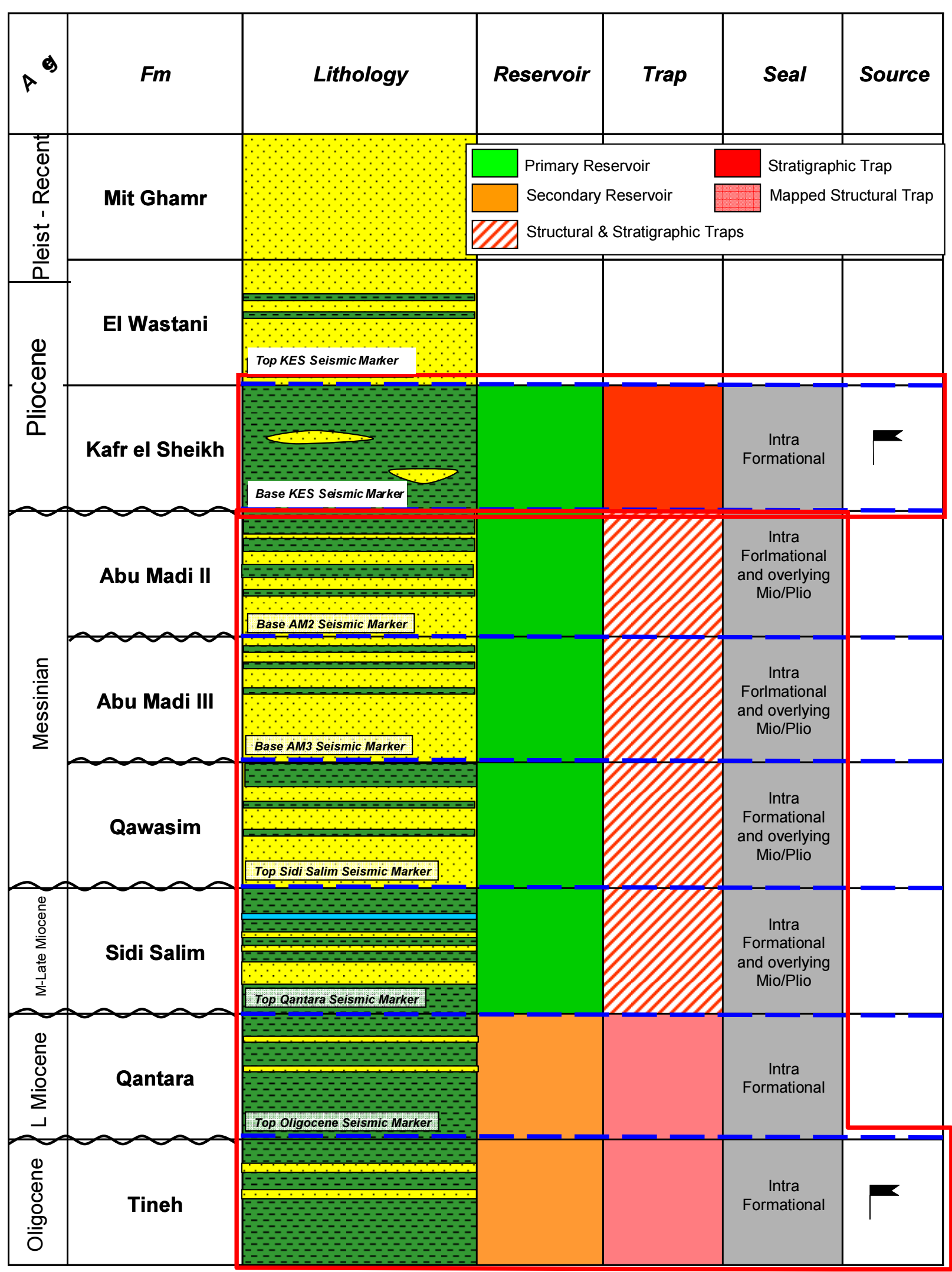

Fig. 2: Nile Delta generalized stratigraphic sequence 


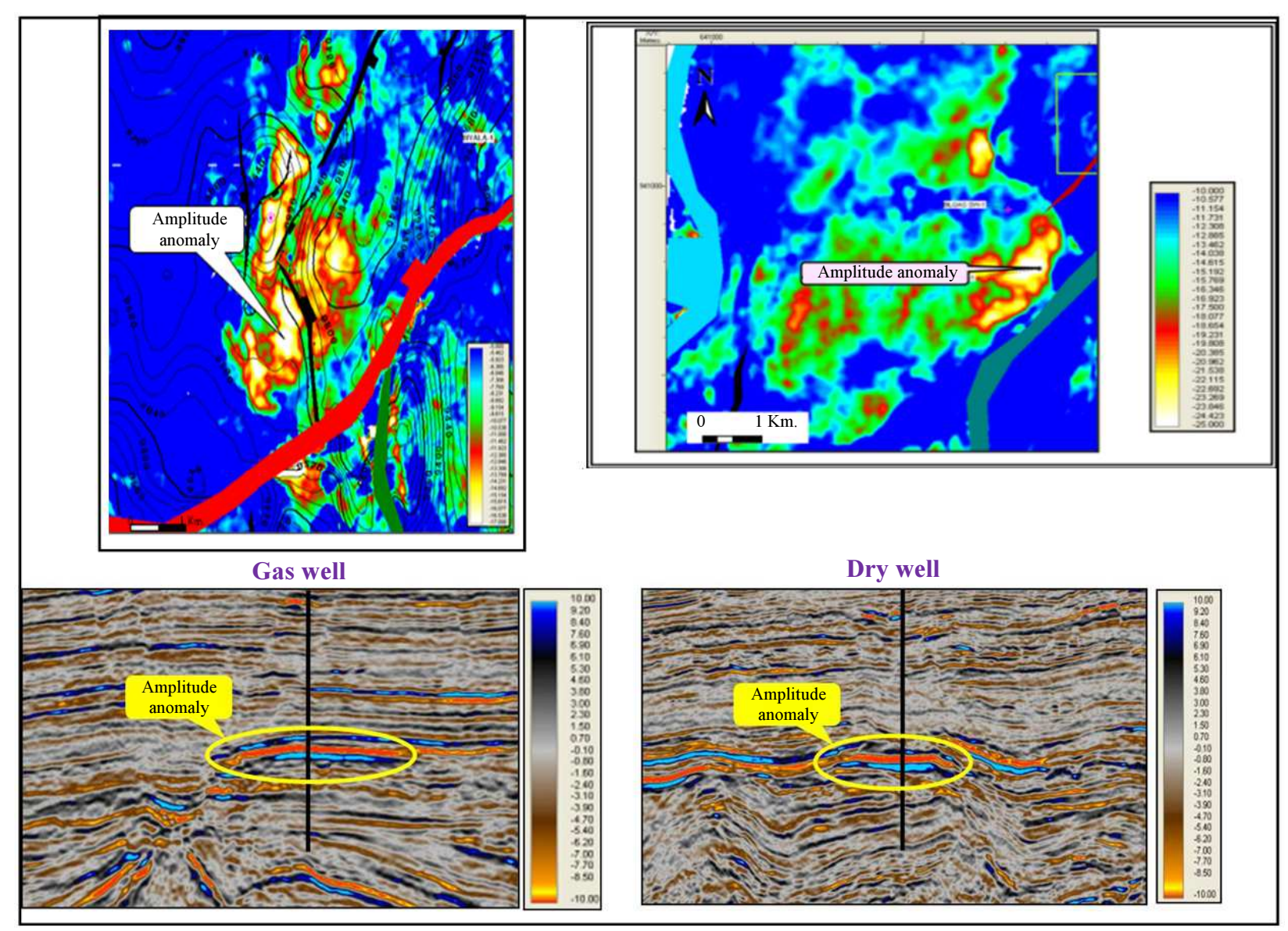

Fig. 3: Two different amplitude anomalies displayed in both the seismic sections and amplitude maps

\section{Methodology}

\section{AVO Theory, Classification and Processing}

About 1900, Zoeppritz and Knott established the theoretical part for the AVO theory (Knott, 1899; Zoeppritz, 1919), knowing the P-wave and S-wave velocities parallel with the densities of the two bounding layers. They advanced equations for plane-wave reflection amplitudes as a function of incident angle. Bortfeld (1961) shortened Zoeppritz's equation, became easier to understand how reflection amplitudes rely on the incident angle and the physical factors. Koefoed defined the relation of the AVO to any variation in the Poisson's ratio across the reflector (Koefoed, 1955).

When the P-wave incident the interface between two different media, the energy of the ray is partially reflected and partially passed as P-waves and changed to S-waves. The reflection angle, incidence angle and the angle of transmission, with the $\mathrm{S}$ and $\mathrm{P}$-wave velocities on both boundary of the reflector, follow Snell's law (Fig. 4):

$$
\frac{\sin (\theta 1)}{\alpha 1}=\frac{\sin (\theta 2)}{\alpha 2}=\frac{\sin (\theta 1)}{\beta 1}=\frac{\sin (\theta 2)}{\beta 2}=p
$$

where, $p$ is the ray parameter, $\theta 1$ is the incident/reflected $\mathrm{P}$-wave angle, $\theta 2$ is the transmitted $\mathrm{P}$-wave angle, $\varphi 1$ and $\varphi 2$ are the reflected and transmitted S-wave angles, correspondingly, $\alpha 1$ and $\beta 1$ are the $\mathrm{P}$ - and S-wave velocities of medium 1 , while $\alpha 2$ and $\beta 2$ are the P and Swave velocities for the second medium. However, the mathematical relations established by these authors, of plane-wave reflection coefficients make it challenging to verify, how the amplitude reflection could change, when the rock properties are changed too.

The Aki and Richards's (1980) approximation is interesting, because it is described in three terms, the first is the P-wave velocity, the second is the density and the third is the S-wave velocity. Their approximation can be described as follows:

$$
R_{p p}(\theta) \approx \frac{1}{2}\left(1-4\left(\frac{\beta}{\alpha}\right)^{2} \sin ^{2} \theta\right)+\frac{1}{2}\left(1+\tan ^{2} \theta\right) \frac{\Delta \alpha}{\alpha}-4\left(\frac{\beta}{\theta}\right)^{2} \sin ^{2} \theta \frac{\Delta \beta}{\beta}
$$

where, $\alpha$ is the two P-wave average velocities on the two sides of the boundary, $\beta$ is the two S-wave average velocities on the two sides of the boundary, $\rho$ is the average 
of the densities of the two media and $\theta$ is the average of the $\mathrm{P}$-wave angles of the transmission and incidence as:

$$
\Delta \alpha=\alpha_{2}-\alpha_{1}, \Delta \beta=\beta_{2}-\beta_{1} \text { and } \Delta p=p_{2}-p_{1} .
$$

Ostrander (1984) was the first who established the reflection coefficients of the gas-bearing sands can be contrasted in an anomalous way by increasing the offset. Since a number of P-wave AVO methods have been derived to use as a lithology and fluid analysis discrimination, including the gradient and intercept analysis (Shuey, 1985) and the weighted stacking method (Smith and Gidlow, 1987). A different arrangement of the Zoeppritz equations was done by Shey (1985), where he replaced the variables in Equation. (2) from $\beta$ to $\sigma$, to illustrate the differences in the Poisson's ratio. The new one of the Zoeppritz relations is:

$$
R_{p p}(\theta) \approx R_{p o}+\left\{A o R p o+\frac{\Delta \alpha}{\left(1-\sigma^{2}\right)}\right\} \sin ^{2} \theta+\frac{1}{2} \frac{\Delta \alpha}{\alpha}\left(\tan ^{2} \theta-\sin ^{2} \theta\right)
$$

where, $R_{p o}$ show the normal incidence reflection coefficient and the second refer to $R_{\mathrm{pp}}(\theta)$ at intermediate angles and the last term illustrate $R_{\mathrm{pp}}(\theta)$ at the critical angle. $A \mathrm{o}$ is the amplitude at the normal incidence that is defined by:

$$
A o=B o-2(1+B o) \frac{1-2 \sigma}{1-\sigma}, B o=\frac{\frac{\Delta \alpha}{\alpha}}{\left\{\frac{\Delta \alpha}{\alpha}+\frac{\Delta \rho}{\rho}\right\}}
$$

where: $\Delta \sigma=\sigma 2-\sigma_{1}$ and $\sigma=(\sigma 1+\sigma 2) / 2$.

Shuey (1985) observed that, for small angles, $\tan ^{2} \theta-\sin ^{2} \theta \approx 0$ (Equation 3) and suggested an approximation, which is valid up to $30^{\circ}$. Hence, this explanation comprises all the relations between $R \mathrm{pp}(\theta)$ and the elastic properties, which needs a velocity model and a fixed Poisson's ratio is also essential. Equation (4) can be shortened to:

$R(\theta) \approx R p+G \sin ^{2} \theta$

where, $R p$ is the normal incidence reflectivity (intercept) and $G$ is often called the AVO gradient (slope), that affected by larger angles and can be obtained by performing a linear regression analysis on the seismic amplitudes.

\section{AVO Classification}

According to the AVO classification for gaseous sand by (Rutherford and Williams, 1989; Castagna and Swan, 1997), there are four AVO classes for the clastic rocks: (1) Class I of gas-bearing sands, characterized by high impedance than the overlying layer. The intercept A is relatively large and positive and the reflection magnitude decreases with the offset faster than the background trend. The product of intercept A and gradient B is negative at the top. These sands lie in quadrant four of the intercept versus gradient cross-plot (Fig. 5). (2) Class II of gas-sands, almost have the same impedance of the covering layer: the normal-incidence coefficient A value is lower than 0.02 in magnitude.

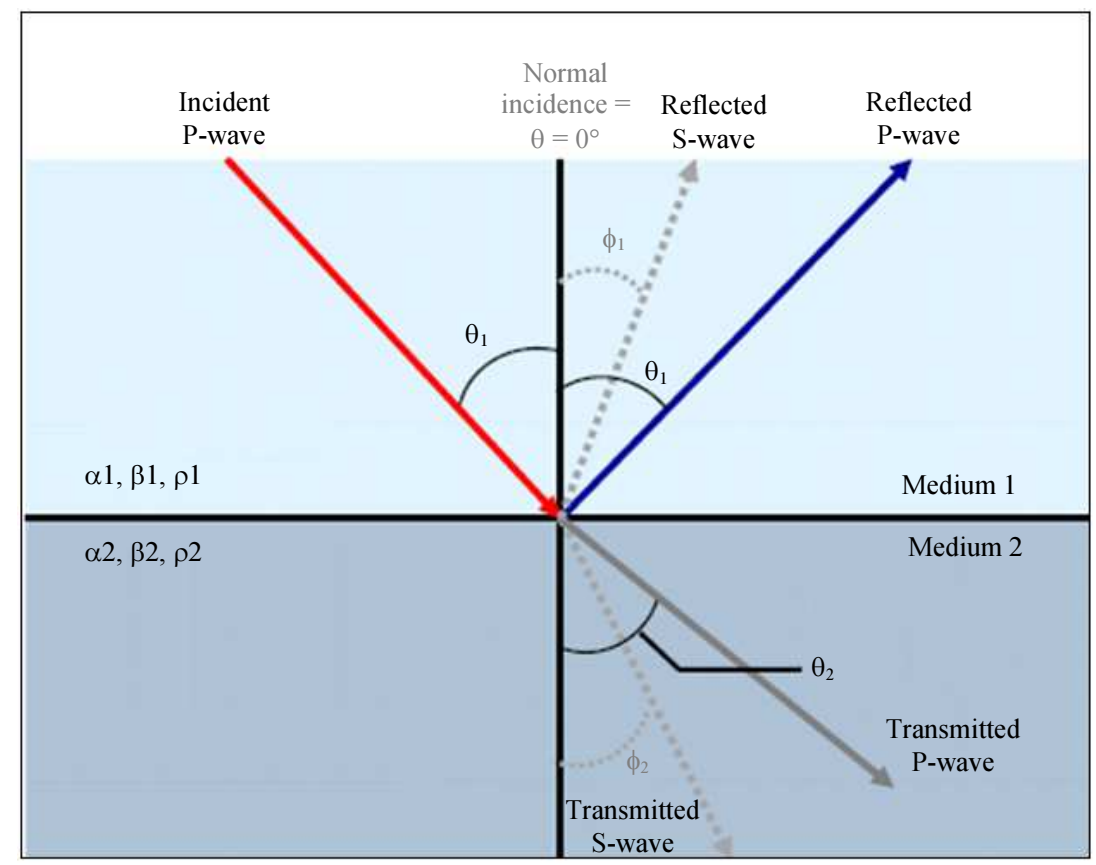

Fig. 4: Reflection and transmission at an interface, for an incident P-wave 


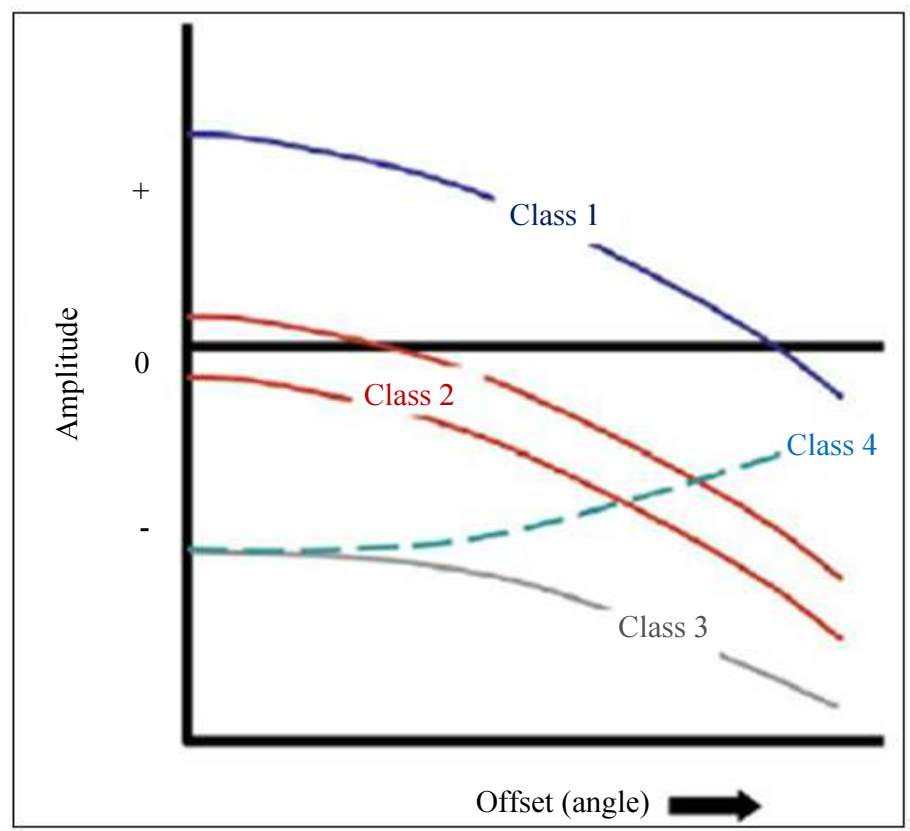

Fig. 5: Classification of the AVO (Rutherford and Williams, 1989), with the addition of Class IV by Castagna and Swan (1997)

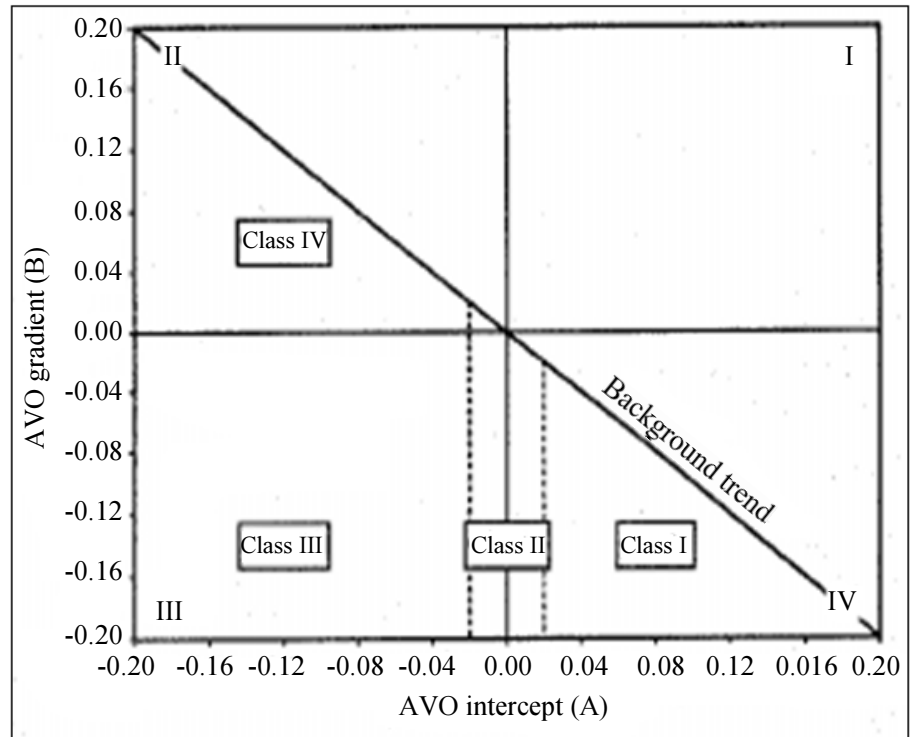

Fig. 6: AVO intercept (A) versus gradient (B) crossplot, showing four possible quadrants (Castagna et al., 1998).

The reflection magnitude may increase or decrease with offset and may reverse polarity, the product $\mathrm{A}^{*} \mathrm{~B}$ is indeterminate. This type of sand is usually moderately compacted and consolidated and can lie in any of the quadrants two, three, or four. Class II of sands may or may not correspond to the amplitude anomalies on stacked data.(3) Class III of gas sands, have the lower impedance than that of the overlying unit (classical bright spots). The A value is negative and large, the reflection amplitude increases with offset, the product A*B is positive at the top. (4) Class IV of gas sands, is characterized by lower impedance than the overlying unit. The A value is large and negative, but the amplitude reflection reduces when the offset increase, the product $\mathrm{A}^{*} \mathrm{~B}$ is negative at the top. Class IV of gasbearing sands, arise from the permeable sand is overlaid by a high-velocity bed, such as siltstone, cemented sand, hard shale, or carbonate. Then the gradient, from class IV gas-bearing sand could be same to the one from class IV of brine sand, these gas sands possibly will be challenging to distinguish by the conventional method from the offset stacks (Fig. 6). 


\section{AVO Processing}

The major problem in the AVO processing is to combines processing parameters and algorithms in a same way, generating a minimum of amplitude bias. Ramos suggested that the AVO technique success relies on the applied processing sequence, particularly in presence of reverberations and strong multiples (Ramos et al., 1999). The main aim of seismic data processing for the AVO modeling is to extract the rock properties, along with the structural image enhancement. To do an AVO analysis, the True Amplitude Recovery (TAR) necessary be conserved. Consequently, over attention should be taken to preserve the amplitude variation, due to the variation of the fluid content and lithology. Following to Yilmaz, there are 3 important processing steps (Yilmaz, 2001):

- The seismic data amplitudes must be preserved, to detect the amplitude variation with offset

- The broadband signal has to be kept with a flat spectrum

- Pre-stack inversion should be applied to the CDP gathers, to produce the different attributes

\section{Wavelet and Seismic Tie}

The critical problem in forward modeling is achieving an actual earth model by matching. This match is dependent on a selection of the appropriate wavelet that used for estimating the model response. Seismic forward molding using a Ricker wavelet consider dominant frequency used in computing the response. This wavelet is zero phase and considers maximum amplitude at zero time. Seismic data acquisition usually adopts many sources such as dynamite that generates minimum phase wavelet and vibroseis generates zero phase wavelet. The minimum phase of wavelet has a lower resolving power than zero-phase. A right selection for wavelet requires a good experience of seismic waveform because the source wave form is known at the surface but changes during wave propagation in earth subsurface making it difficult to estimate the waveform. It is common to get an estimated to seismic wavelet seismic data using the statistical method (Nandam, 2016). During the synthetic seismogram generation, some operators use basic wavelet that is measured through synthetic seismogram generation, but the common practice nowadays is extracting the wavelet from post /pre-stack seismic section as statistical wavelet or estimate wavelet from seismic trace nearby the well place and comparing the results with the impedance reflectivity from well log data (Chopra and Sharma, 2016), (Fig. 7).

Seismograms, which is symmetrical with the maximum amplitude at time of arrival.2) Minimum phase wavelet has asymmetrical concentration of energy (front loaded) following its arrival time.
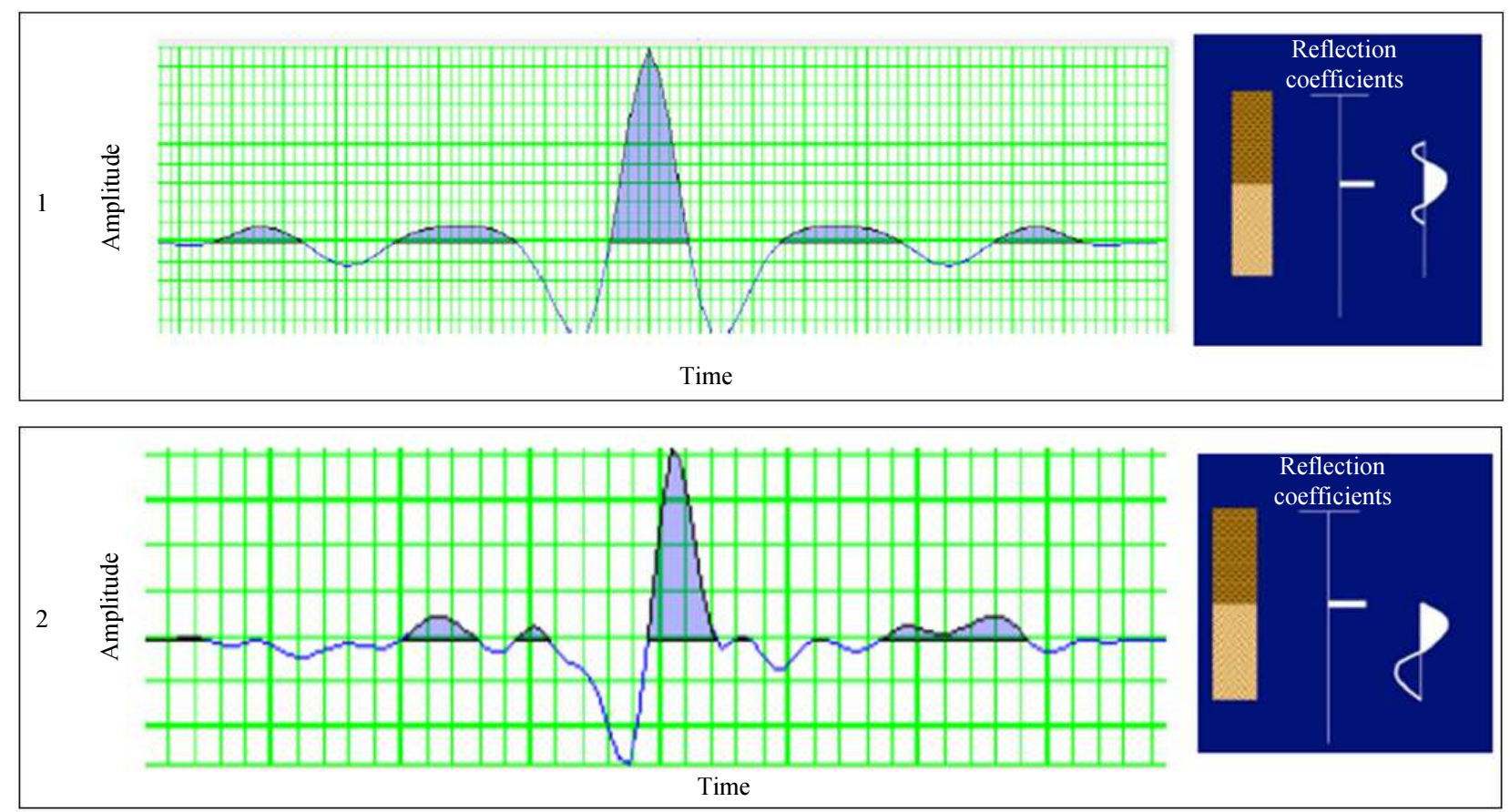

Fig. 7: Shows the wavelet characteristics. (1) Zero phase wavelet, commonly used for generating synthetic seismograms, which is symmetrical with the maximum amplitude at time of arrival.2) Minimum phase wavelet has asymmetrical concentration of energy (front loaded) following its arrival time 


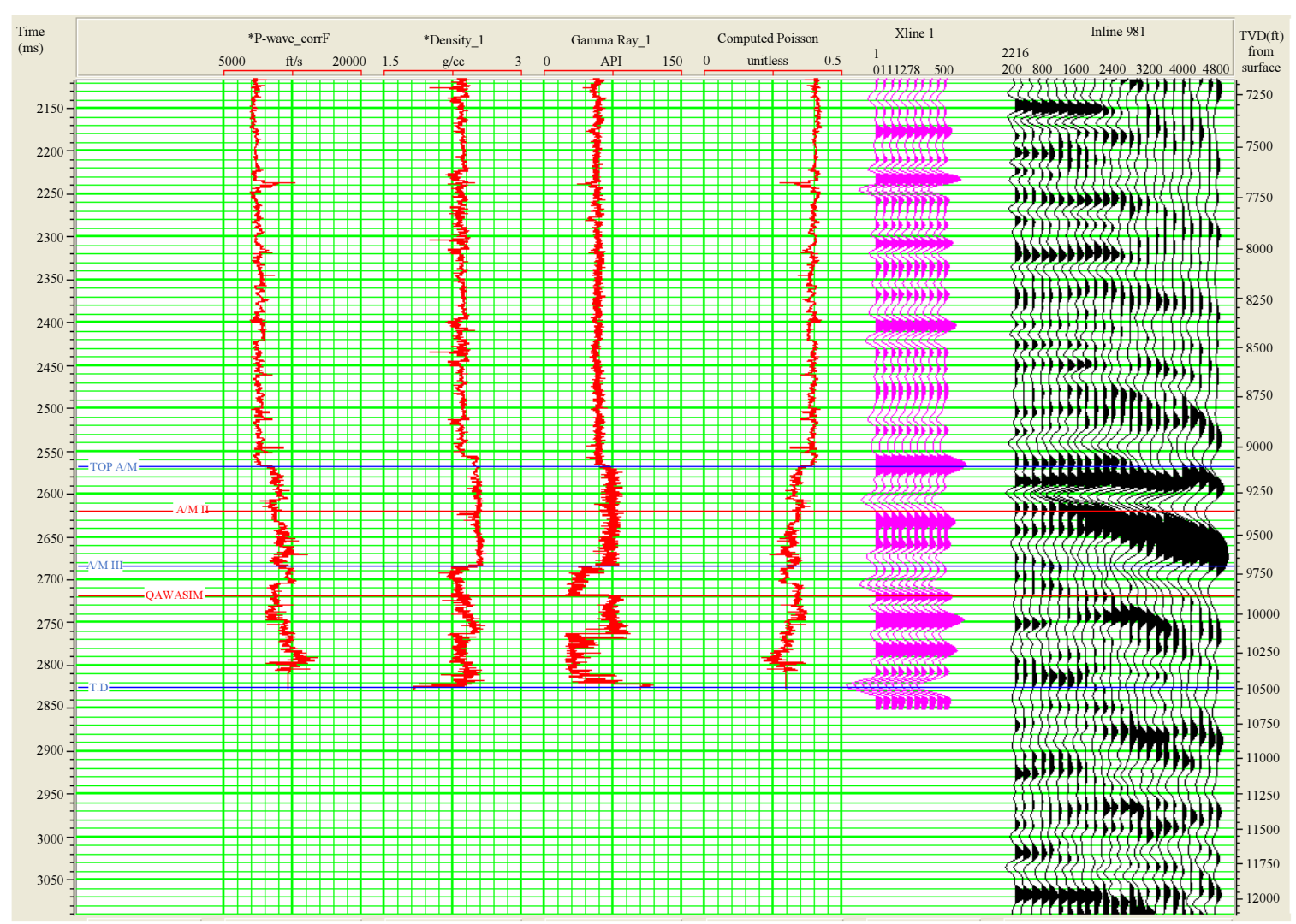

Fig. 8: Synthetic generation, showing the best matching results

AVO modeling workflow starting with the loading and checking of the data of the Electric logs, loading the seismic data (CDP gathers), wavelet extraction (in-house zero-phase $25 \mathrm{~Hz}$ wavelet was extracted from the seismic, gives much better matching results) and synthetic generation. In order to make a good AVO modeling and invert the seismic data for rock properties, the seismic data necessity to calibrate to the geology met in a well. This process implicates the comparison between the real seismic data with the synthetic trace (Fig. 8). If the calibration results give a good correlation, then seismic can be in terms of the geology. If the calibration results were bad, there will stay major uncertainty in the interpretation of seismic data.

\section{Super Gather}

This process refers to gather traces within a box, which is well-defined by the range of the offset and a CMP range or it is the procedure of creating average CDPs (the averaging was done by collecting the neighboring CDPs and add them together) to improve the signal to noise ( $\mathrm{S} / \mathrm{N})$ ratio, while maintaining the AVO amplitude information, at the same time the offset dimension is preserved (Fig. 9).

\section{Converting from the Offset Domain to the Angle Domain}

As stated, the angle of incidence at which the seismic ray strikes the concerned horizon. There is a nonlinear relation between the offset and angle, when they are similar, which must first be involved in the analysis sequence which requires to use angle instead of offset. We called this type of transformation amplitude versus angle (AVA) quite than AVO. Caring the decrease of the incident angle with depth, whereas the angle is constant for a fixed angle with depth. The conversion from constant offset to constant angle necessitates the identification of the relation between $X$ and $\theta$. For an ideal solution, a full ray tracing necessity be done (Figs. 10 and 11):

$\tan \theta=\frac{X}{2 Z}$

where, $\theta$ : incidence angle, $X$ : offset and $Z$ : depth. If we recognize the velocity to the target zone, we can write:

$$
Z=\frac{v t o}{2}
$$

where, V: velocity (average or RMS) and $t_{0}$ : total zero offset travel time. Substituting Equation (7) in (6) gives:

$$
\tan \theta=\frac{X}{v t o}
$$




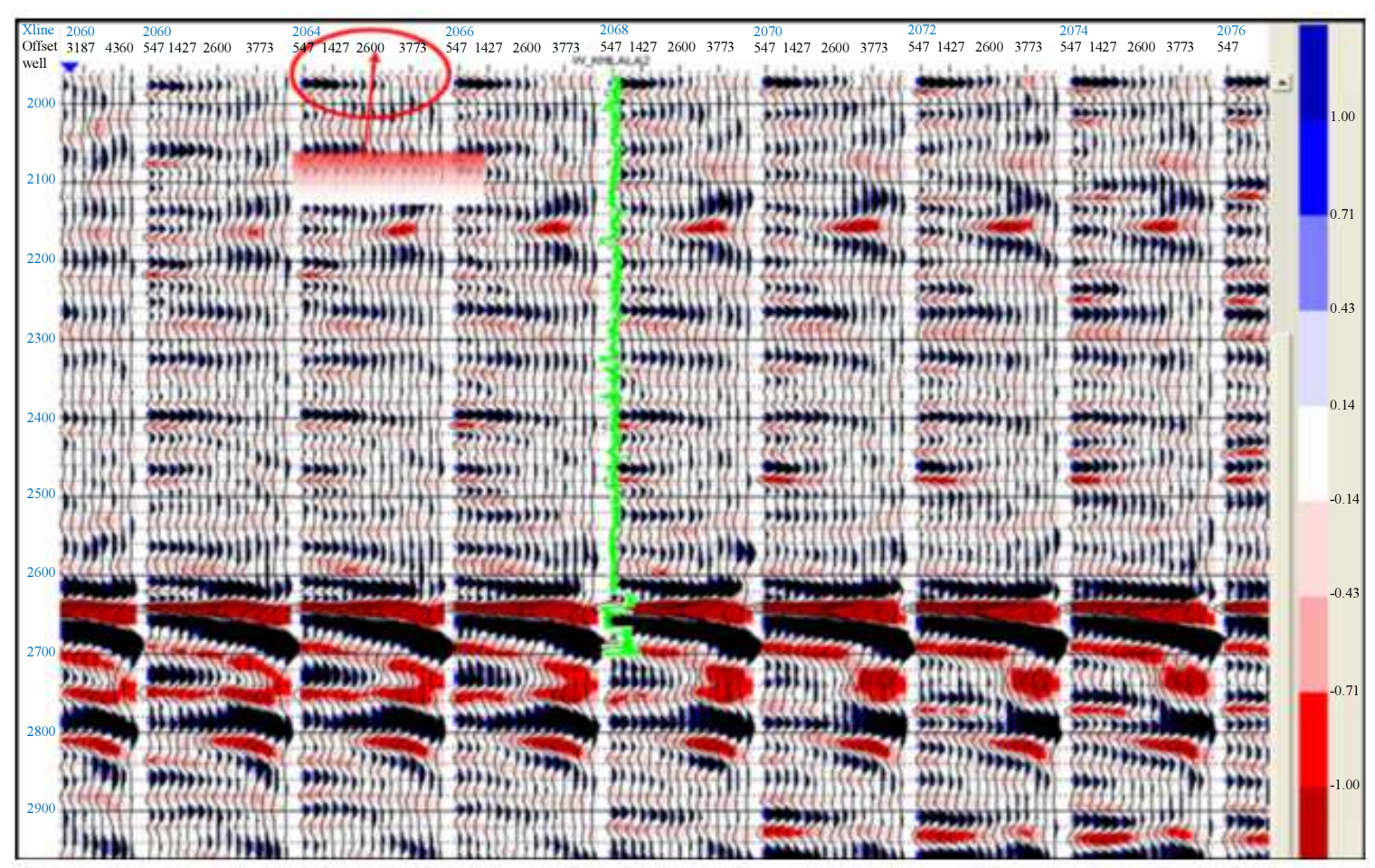

Fig. 9: Super gather (common offset stack) generated from the 3D seismic data

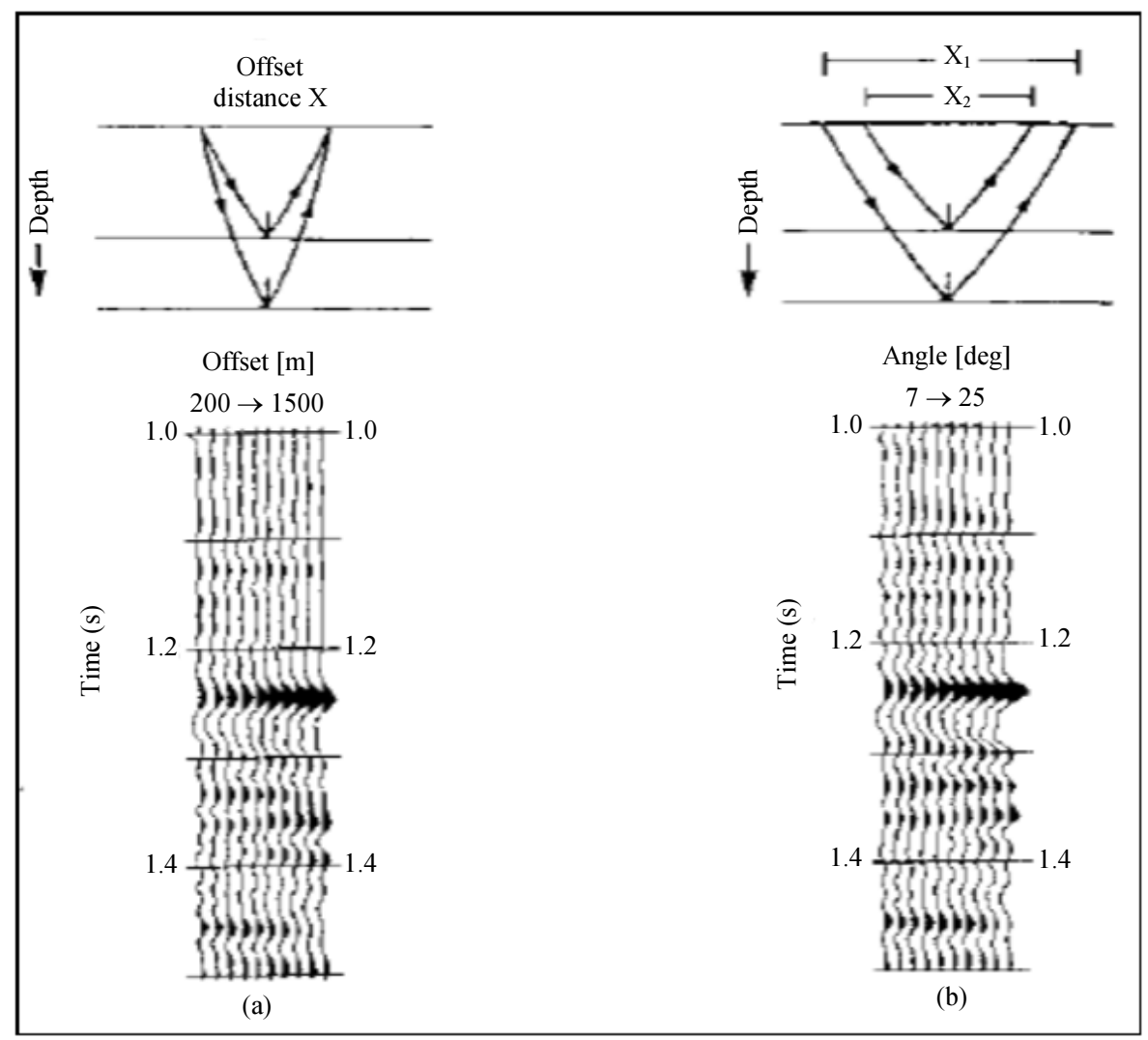

Fig. 10: (a) Shows the AVO response and (b) shows the transform of (a) in AVA (amplitude versus angle) (Western Geophysical) 


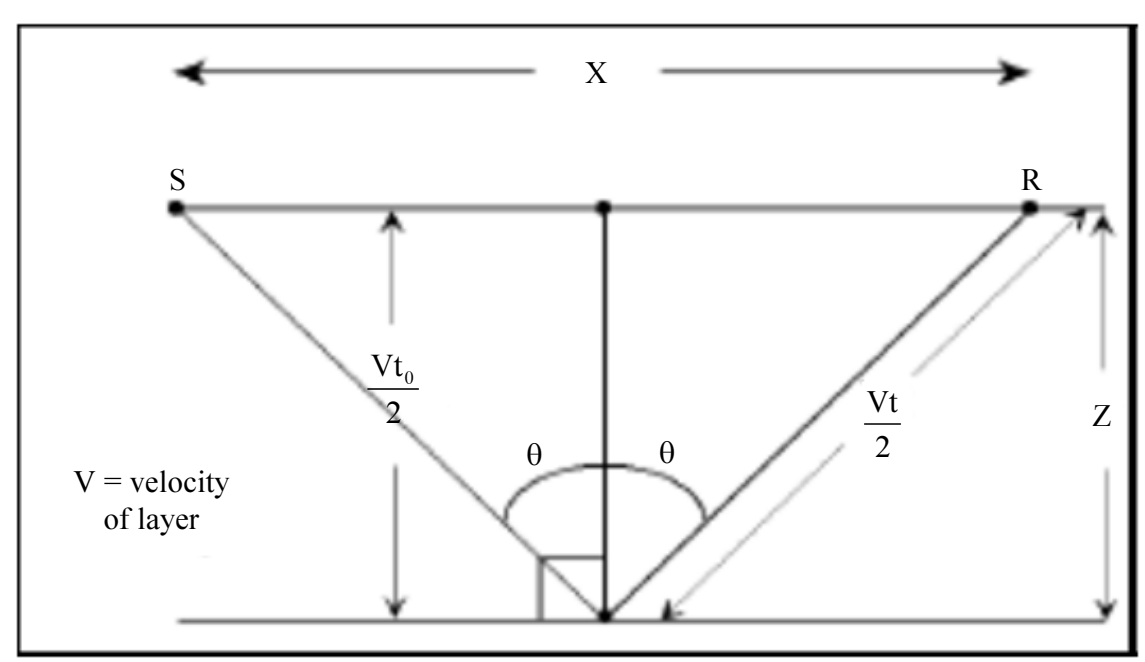

Fig. 11: Ray path geometry for a single shot-receiver pairing a constant velocity medium

This provides the offset to angle mapping. By reversing Equation (8), we can acquire the mapped the angle to the offset:

$X=$ Vto $\tan \theta$

From Equation (9) let us draw the amplitude on the offset gather to amplitude on the angle gather. All these previous equations can apply for a particular layer only. Another calculation can be used for the multi-layer involves the ray parameters $\mathrm{p}$ and total travel time $\mathrm{t}$, where:

$$
\frac{\sin \theta}{\cos \theta}=\tan \theta=\frac{X}{V t o}
$$

\section{Angle Gathers}

In this process, each input sample is mapped to its corresponding incident angle. For this process, the super gather volume was used as an input. The velocity data necessary for this process can be derived from well data or from the stacking velocity. Another benefit is the generation of super and angle gathers is to plot the offset against the incidence angles in order to verify the limit of the far offset or far angles that can be trusted.

\section{Range Limited Stacks}

Those are the CDP stacks averaged over specified offset or angle ranges. The input for this process is the super gather. This step has to do with dividing the data into both near and far angle stacks, as shown in (Fig.12).

Therefore, the amplitude anomaly can be monitored in both stacks (Near and Far), hence helping in providing information about the amplitude behavior with offset.

As a result, it is recommended to generate those stacks, using the velocity derived from the well data (due to the high degree of accuracy of these extracted velocity data acquired from the VSP data inside the well itself rather than the stacking velocity model estimated by the processing every 1 or $0.5 \mathrm{~km}$ CMP surface seismic data), after making a good seismic matching to well tie in order to make quality control for the output.

\section{AVO Reflectivity Attributes, Inversion and Interpretation}

The AVO attributes represent the output, which can be obtained from the AVO analysis. The AVO response of a reflector is described by two parameters: the intercept or reflectivity (amplitude) at the zero-offset and the gradient of the amplitude variation with offset.

Figure 13 illustrates the AVO response derived from the intercept and gradient volumes. In this figure, the intercept showed by the trace data, whereas the colors denote the intercept $\mathrm{x}$ gradient, which indicates the AVO anomaly. By calibration of this AVO anomaly with both the gamma-ray $\log$ and the top pay of gas well, it has been found that there is compatibility between the AVO response, the sand reservoir and the top-pay zone of the well.

\section{Crossplot}

Some of the challenges is to distinguish between the source of the different points on the crossplots. Clearly, you can color them. Crossplots work for a specific trace nevertheless; it will be tough to the seismic data, whereas the window is determined in both time and CDP. The Verm and Hilterman's principle is to define the abnormal values and redisplay them again on the seismic section (Verm and Hilterman, 1994). Take in consideration, they use the altered shape of Equation (1):

$$
R(\theta)=R p \cos ^{2} \theta+\frac{\Delta \alpha}{(1-\sigma)^{2}} \sin ^{2} \theta
$$

where, RP is the Normal Incidence Reflectivity and $\frac{\Delta}{(1-\sigma)^{2}}$ is the Poisson ratio. 


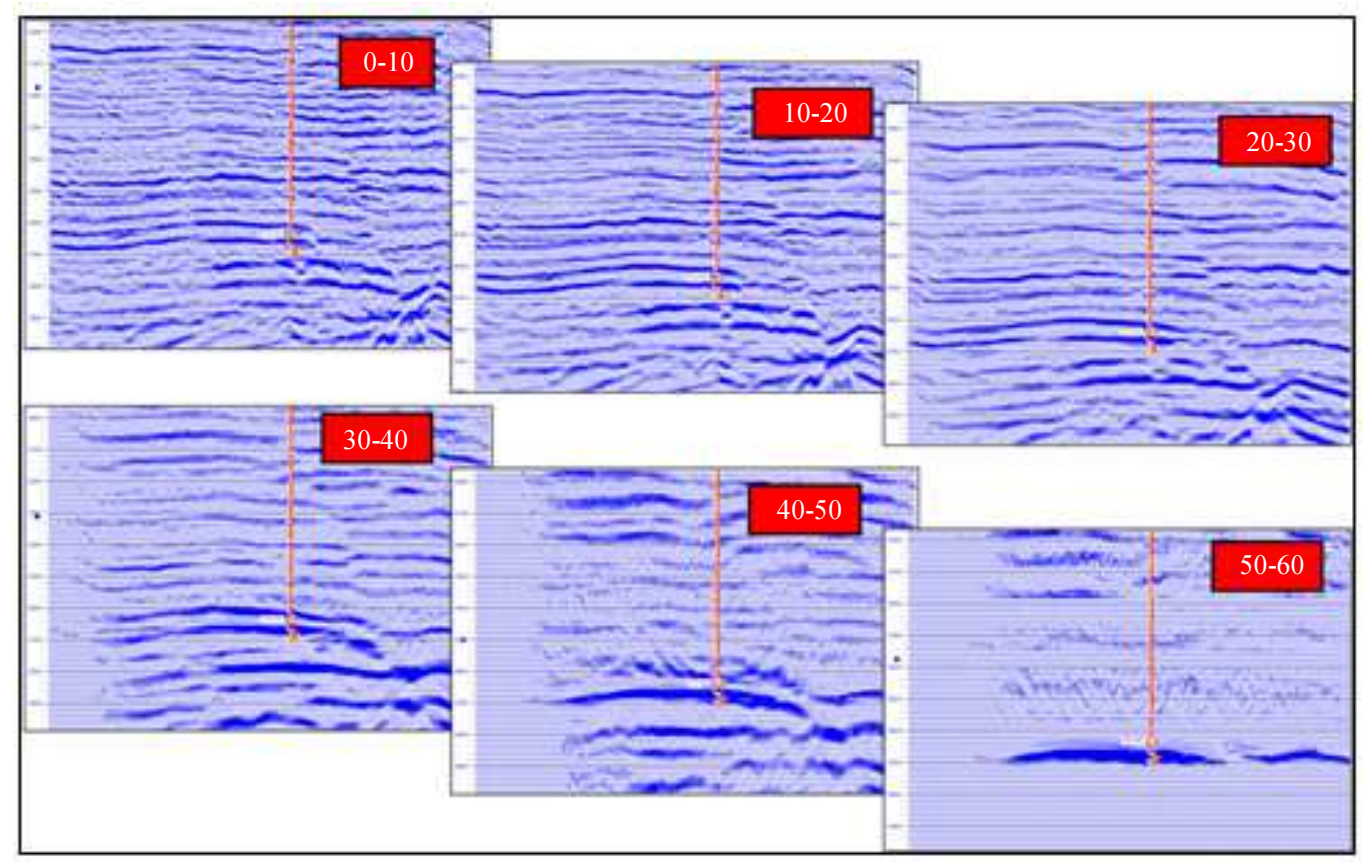

Fig. 12: Range limited stacks extracted from the own 3D seismic data (Near- and Far-angle stacks), to monitor the amplitude variation with different angles

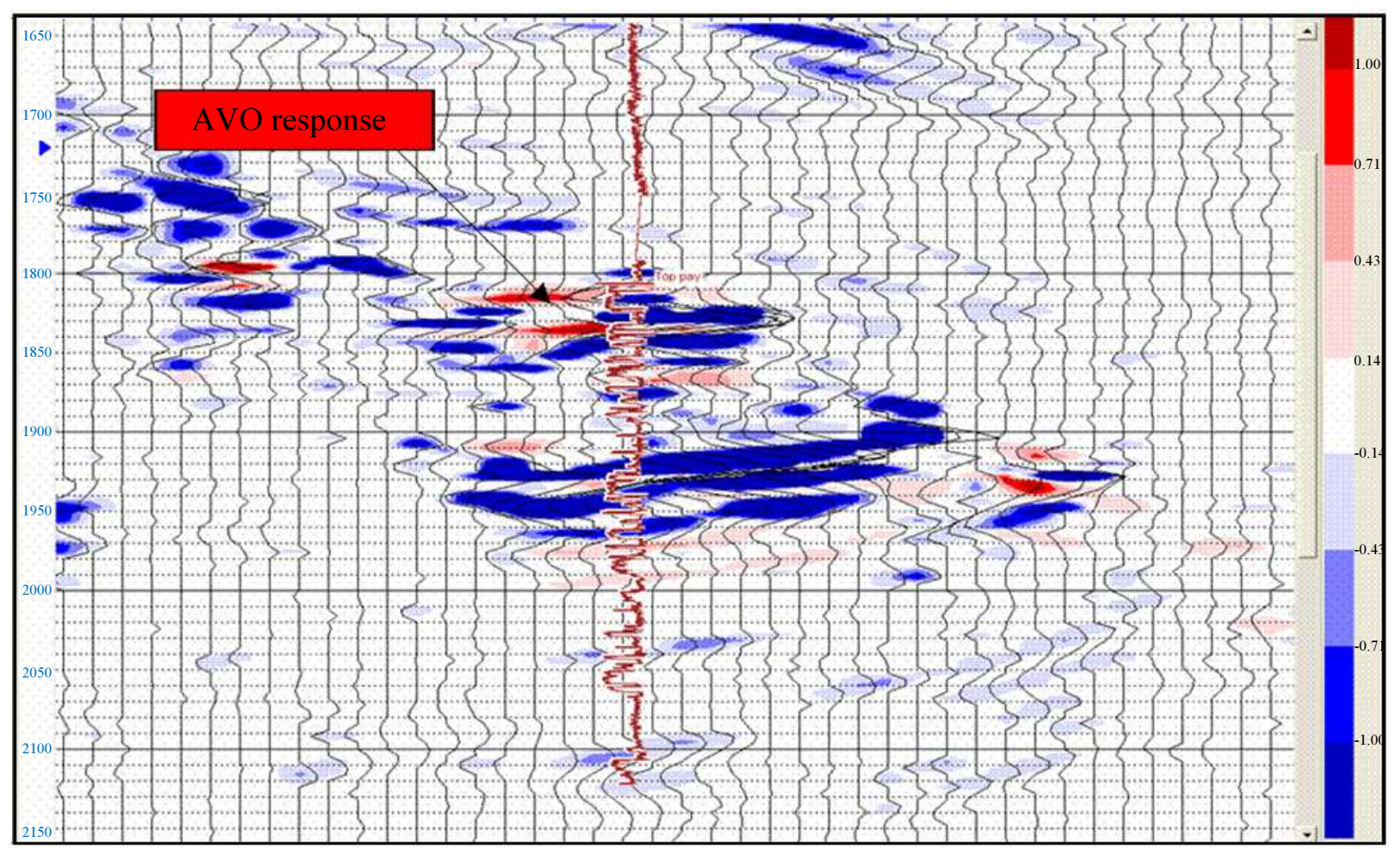

Fig. 13: Product of the intercept and gradient $(A * B)$, showing the AVO anomaly at the gas-bearing sand

A more practical approach, that has been done, is to cross-plot the intercept and gradient for all the time samples at all the trace locations within an aerial window. This has the significant advantage of providing the ability to 
consider more than, just the sample of the seismic event that has been picked. Information about an interface is contained in the whole wavelet, not just the peak or trough. Deviation from this regime may be a hydrocarbon indicator. The intercept and gradient pairs move more away from the background trend, with a decrease in the fluid density, so that gas sands will be the most well-separated (Fig. 14). The degree of shift is to be controlled by the stiffness of the rock, its porosity and its fluid content, as well as the AVO interpretation, using this technique, which was done in this study by: (1) defining the background trend around the origin (yellow color); (2) the two points, which lie outside this trend, which have been highlighted (blue indicates top-gas zone and grey indicates base-gas zone and (3) these anomalies are dropped to the seismic trace and calibrated with the well results.

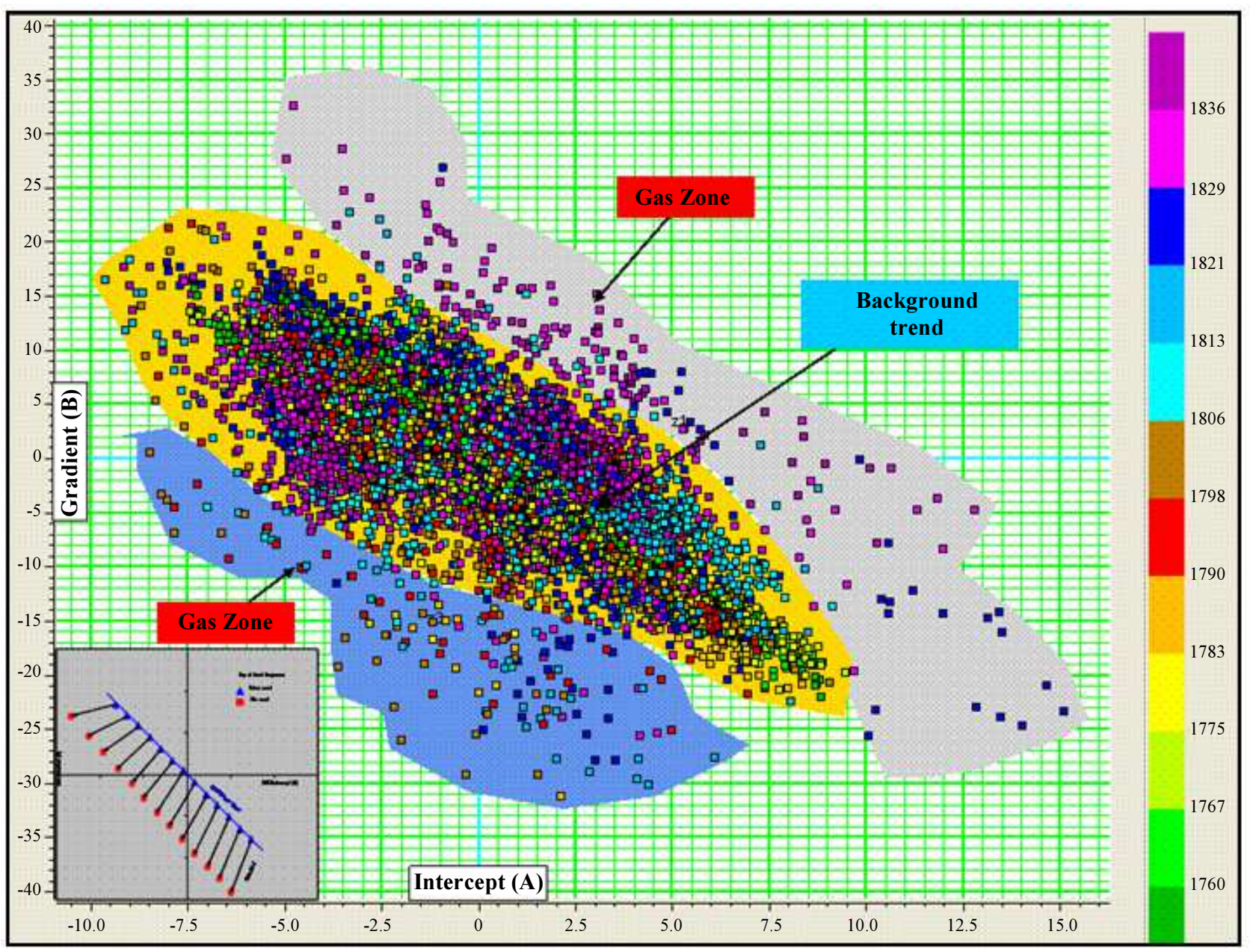

Fig. 14: Crossplot for the intercept vs. gradient

\section{Pre-Stack Inversion}

Seismic inversion is the convert the seismic data to a measureable rock-properties or fluid contents useful as for the hydrocarbon reservoirs (Hampson et al., 2005). It involves extraction of acoustic impedance from seismic data (P-impedance the product of the density and P-wave velocity) that help to make predictions of important reservoir properties like lithology and porosity. Inversion as indicated from the name is the inverse of a model of the earth properties, then mathematically simulates physical properties on earth model and outputs a modeled response. If assumptions and the adopted model are accurate the output should be a replica to the real data. Conversely, inversion begins with a recorded seismic data trace then gets rid of the effect of an estimated wavelet and then at every time sample we create values of acoustic impedance (Barclay et al., 2008) (Fig. 15).

Seismic inversion has some advantages as the following: (1) Seismic inversion provides better resolution stratigraphic images because inversion 
removes wavelet effects like as noise, tuning through deconvolution. (2) Seismic inversion considers acoustic impedance which requires merge and approximately matches seismic section data with well log data. Thus gives better prediction for reservoir properties because inversion removes wavelet effects. (3) Acoustic seismic amplitude is convert to create rock properties as impedance. Using rock physics, it is probable to construct reservoir constraints that can be used in fluid simulation such as fluid saturations and porosity (Latimer et al., 2000). Seismic inversion involves quite a few classes including post or pre-stack, stochastic or deterministic and usually contains real reservoir quantities like well logs and cores (Nastaran and Mokhtari, 2016). Inversion has been applied on poststack seismic data for volume extraction of acoustic impedance then use inversion results to predict lithology parameters such as porosity and saturation. In recent times, inversion can be applied to the pre-stack seismic data to generate both the shear and acoustic impedance cubes volume then use the inversion results for calculation of pore fluid with mean fluid indication (elastic impedance) (Russell, 2014: Hampson and Russell, 2006) (Figs. 16 and 17).

\section{Building the Inversion Model}

The data needs pre-processing before the inversion, all inversion methods involve:

- An initial impedance model.

- Wavelet extraction.

- Integrate both seismic data and log data.

- Precise estimate of wavelet for calculating synthetic for the seismic inversion success and likewise relies on a perfect tie between the well to seismic. As the wavelet shape has effects in the inversion results, subsequent assessment of the reservoir management is dependent to the selected wavelet.

- The inversion is very critical at the well to seismic tie step and as a result essential be precise in the matching part. This needs good experience to repetitive calibration to calculate the phase corrections; i.e., the phase rotation of the seismic data

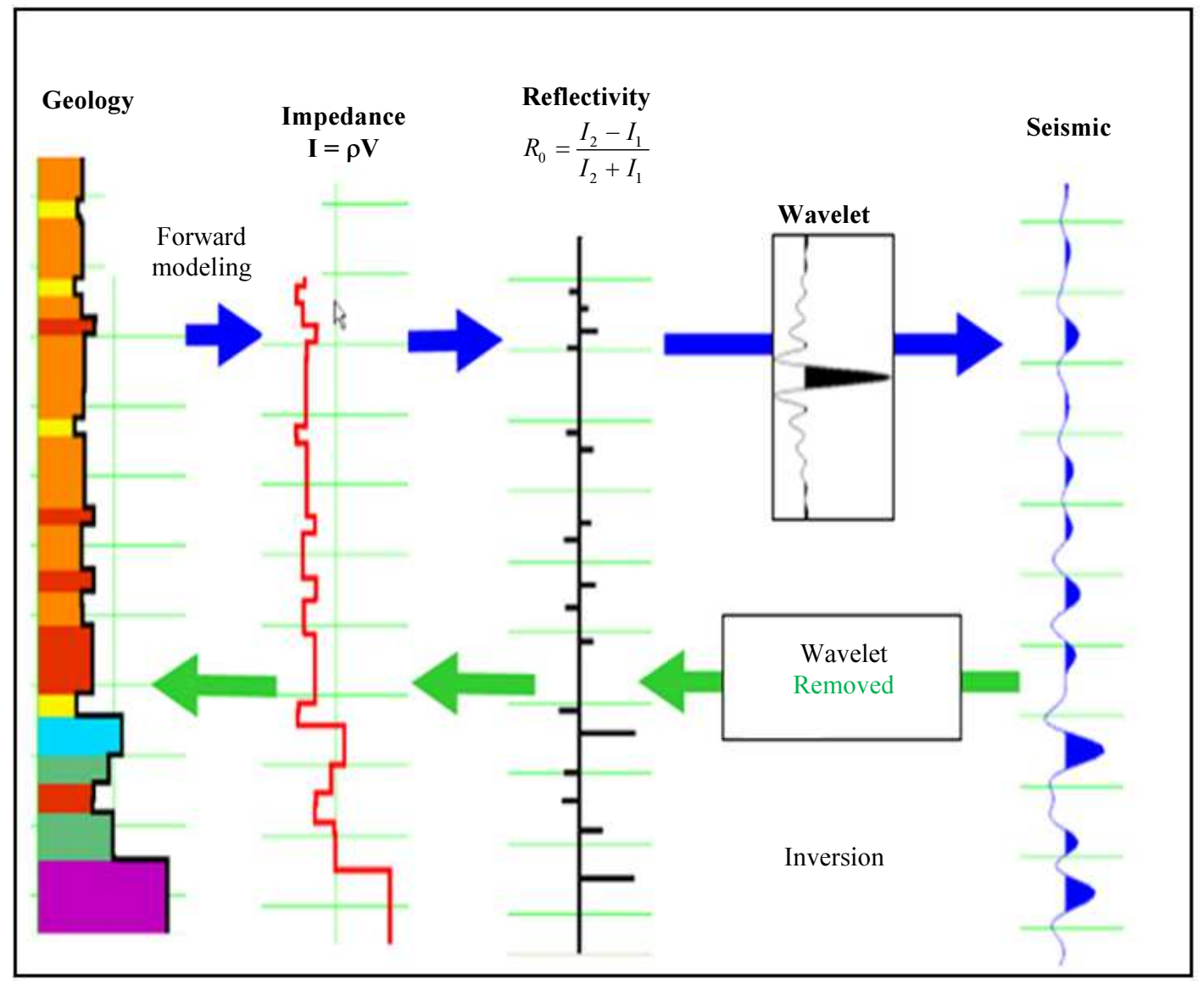

Fig. 15: Comparison between the seismic inversion modeling and forward modeling (Russell B. 2014) 


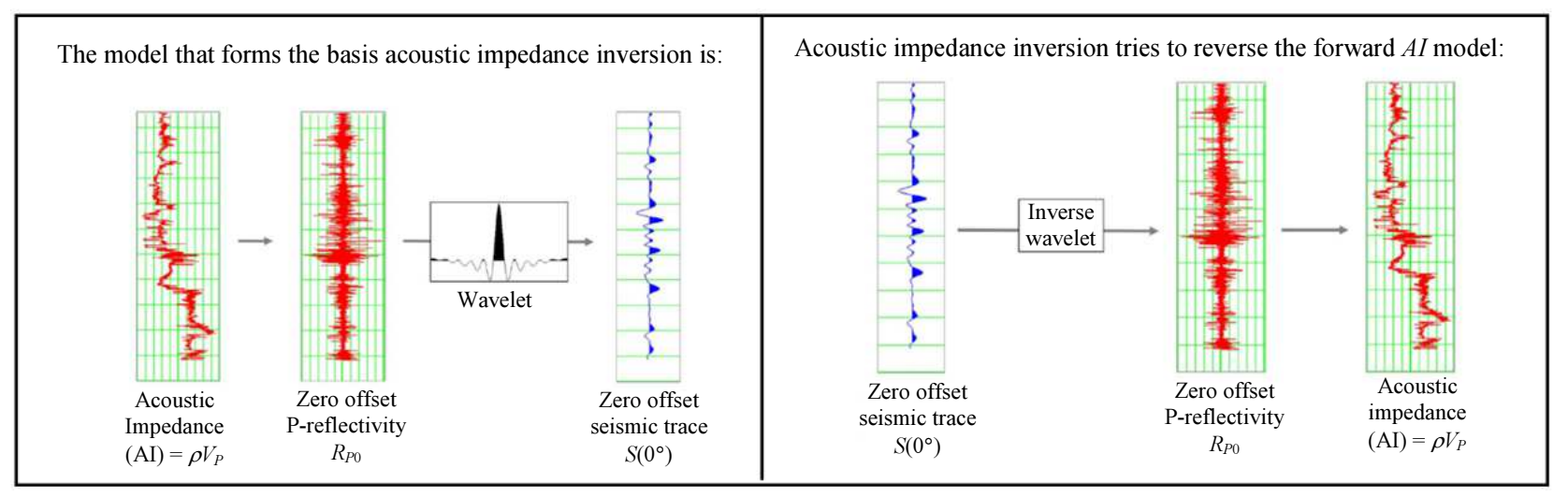

Fig. 16: Acoustic impedance inversion workflow

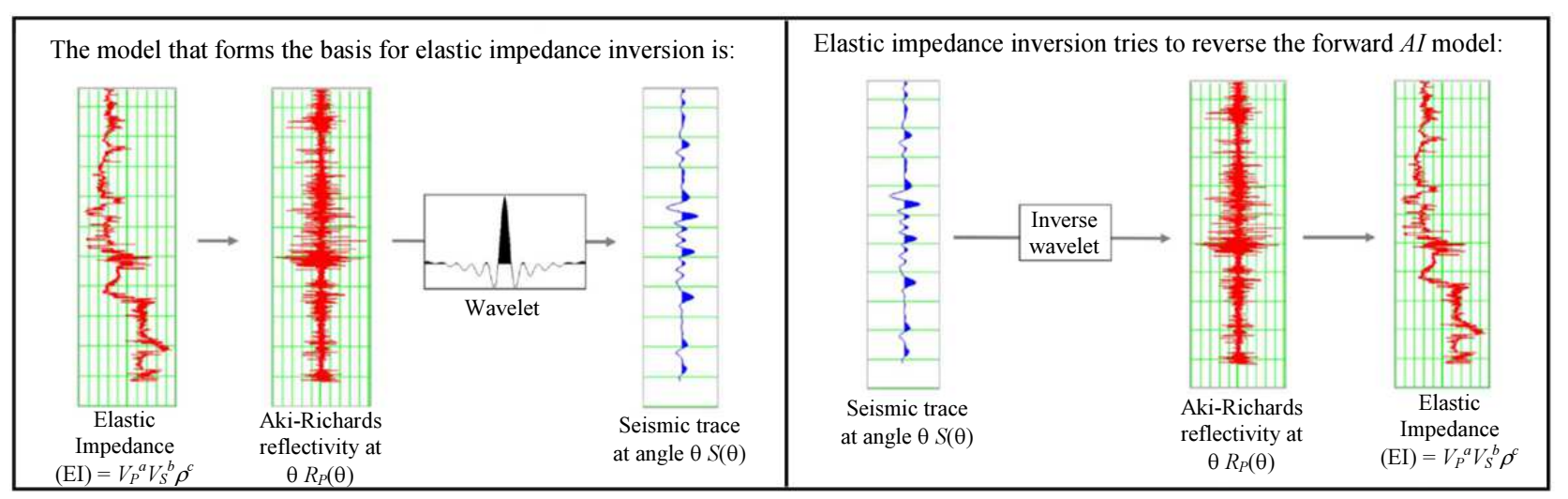

Fig. 17: Elastic impedance inversion workflow

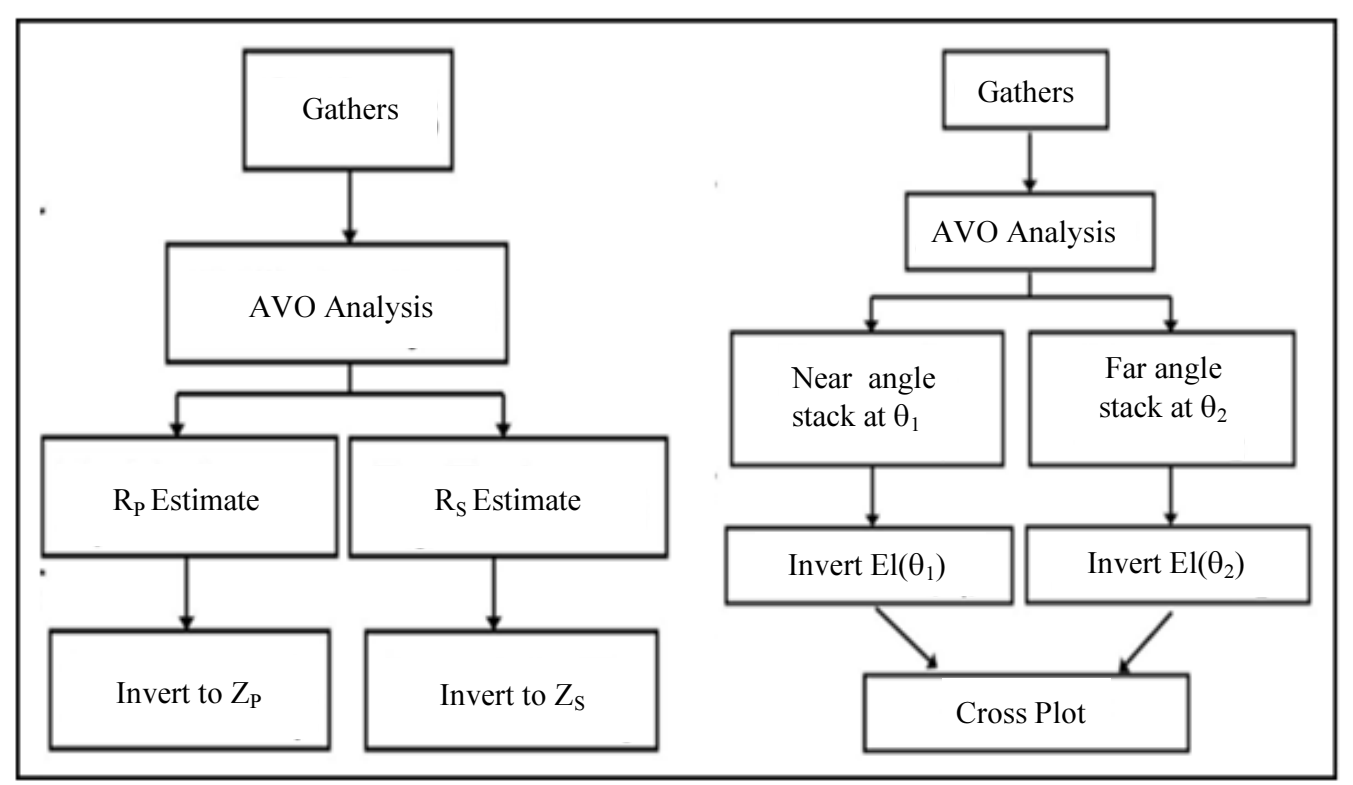

Fig. 18: Workflow chart for the inversion procedures 


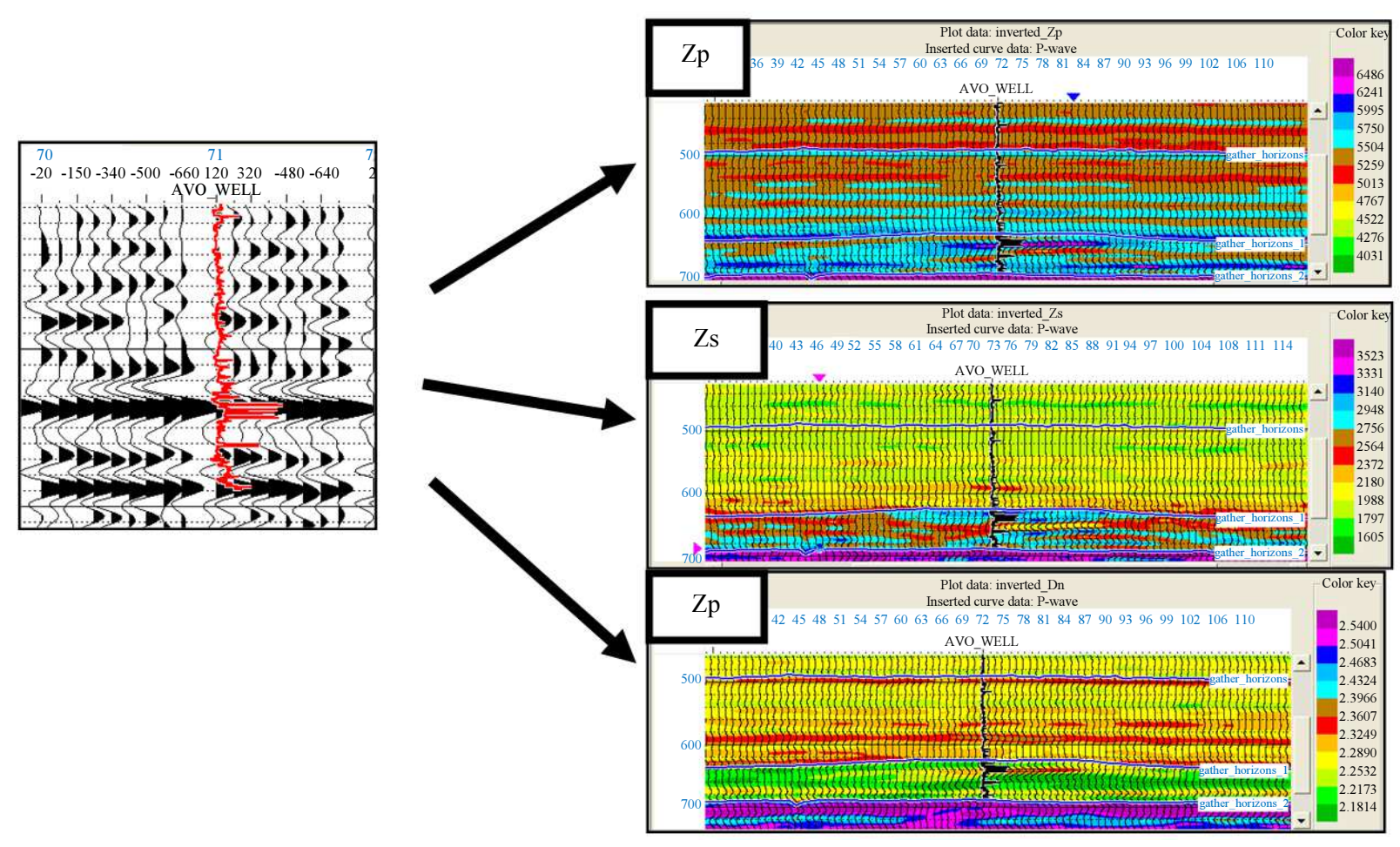

Fig. 19: Final output for the inversion (Acoustic Imped. P-wave, S-wave and density cubes)

In this study, the pre-stack inversion applied, we analyze the fully processed CDP gathers to generate volumes of ZP, Zs and density cubes (Fig. 18). After estimating the RP and Rs from the AVO analysis, as discussed, we can proceed to invert the RP, which will give the p-wave acoustic impedance, $\mathrm{Zp}=\mathrm{P} \mathrm{VP}$ and inverting Rs give the S-wave impedance, $Z s=$ P Vs (Fig. 19).

\section{Results and Discussion}

The results of this research, after a thorough investigation and analysis of the seismic CDP gathers of the two drilled wells, have been concluded that, there is a large difference in the results of the two wells, even though the seismic characters of the amplitude anomalies in the stacked sections are similar to a great extent and have the same structure and stratigraphic sequence. The authors have found out that, the successful well (to the left of Fig. 20) has a full offset coverage. In other words, the near offset is completely recorded, as well as the far offset. Therefore, in this case, there is a true amplitude anomaly, easily recognized by a full offset coverage. Also, the variation of seismic amplitude with the offset can be observed (i.e. the increase of gradient with offset, while this amplitude appears in the near traces and increases gradually to the far traces), which may reveal a hydrocarbon fluid effect.

Therefore, studying the CDP gathers in the near and far offsets and monitoring the amplitude variation with different angles should be taken in consideration in the prospect evaluation stage (helps in validating the prospects before drilling) and in determining the response of the seismic amplitude variation with the offset (Fig. 21). So, it is possible to confirm the amplitude anomaly, if it is related to hydrocarbon or not. Concerning the results of the inversion, by determining the density, the fizz water problem can be solved. Figure (22) elucidates the P-wave inversion final result whereas the P-wave low impedance denotes the gas sand. The results of the inversion around a certain prospect can be tolerated with the closest wells.

Moreover, the outcomes of the pre-stack inversion will assist in the reservoir quality evaluation (Fig. 23). Accordingly, there are three cases, the first of which is the upper one for a non-economic gas well, where the slight decrease in the acoustic impedance can be seen, owing to the weak dissimilarity between the gas sand and the overlying shale, which may indicate a bad reservoir quality in this well. The second is the middle case for a gas well, where a sharp contrast between the shale and the gas sand can be seen, which is confirmed by the sharp decrease in acoustic impedance in the pay zone. The third is the lower case for a prospect which resembles, to a great extent, the middle case. Therefore, from this display, the reservoir quality in gas wells can be evaluated which will also help in the prospect evaluation. 


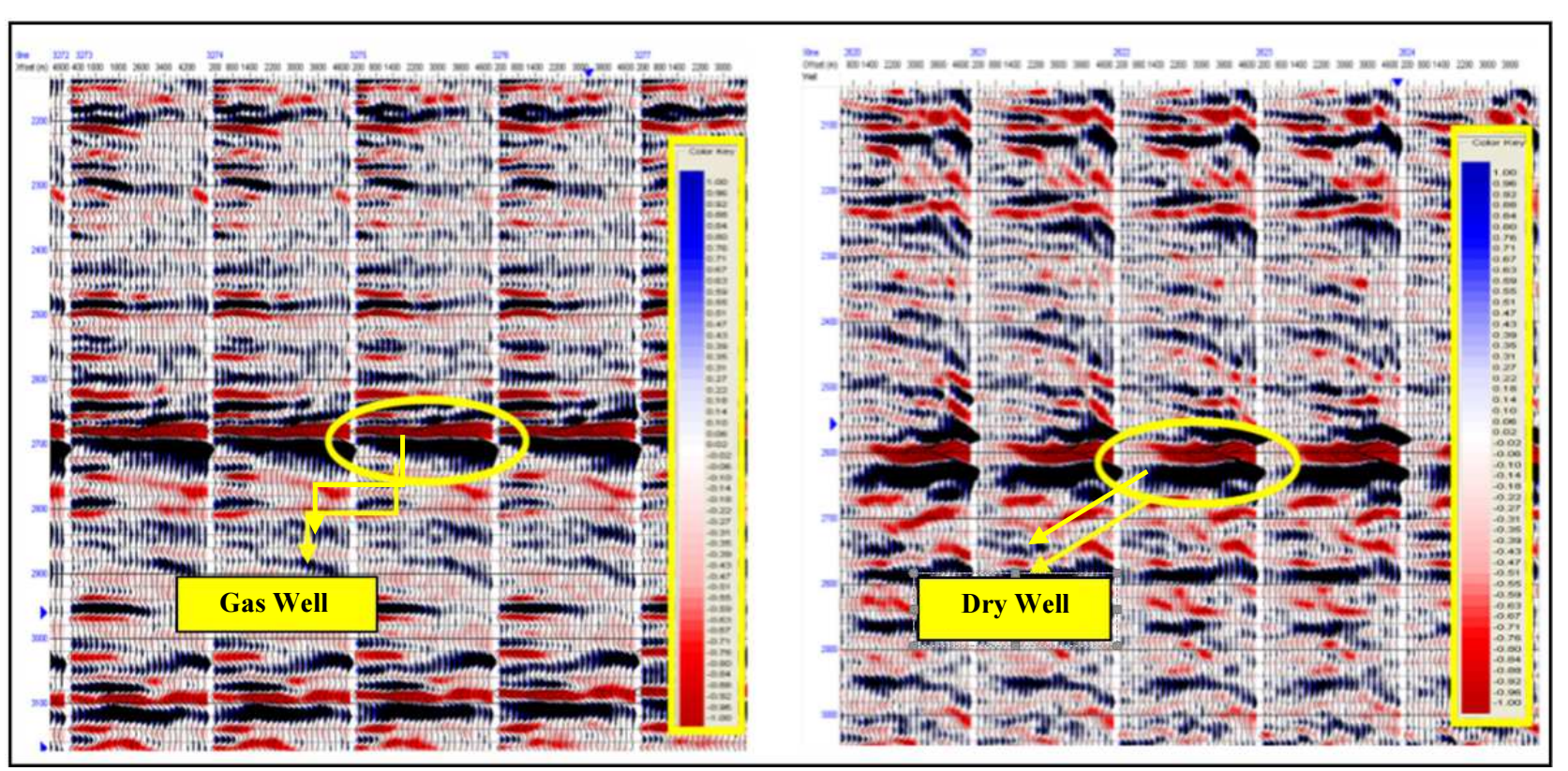

Fig. 20: CDP gathers for both the gas-bearing and dry wells

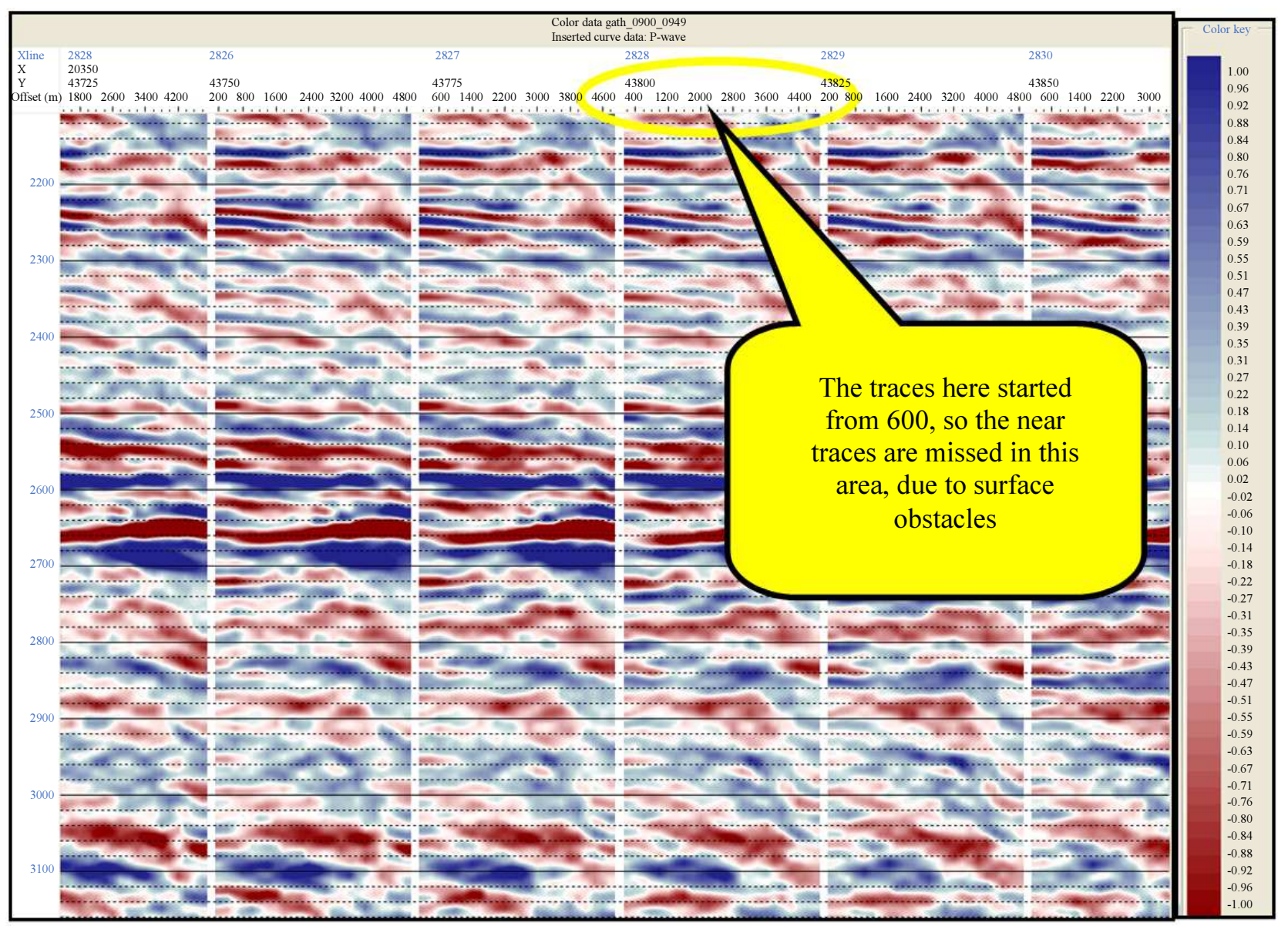

Fig. 21: CDP gather shows the missing of near traces 
Mohamed Hussein et al., / American Journal of Engineering and Applied Sciences 2019, 12 (3): 368.386 DOI: 10.3844/ajeassp.2019.368.386

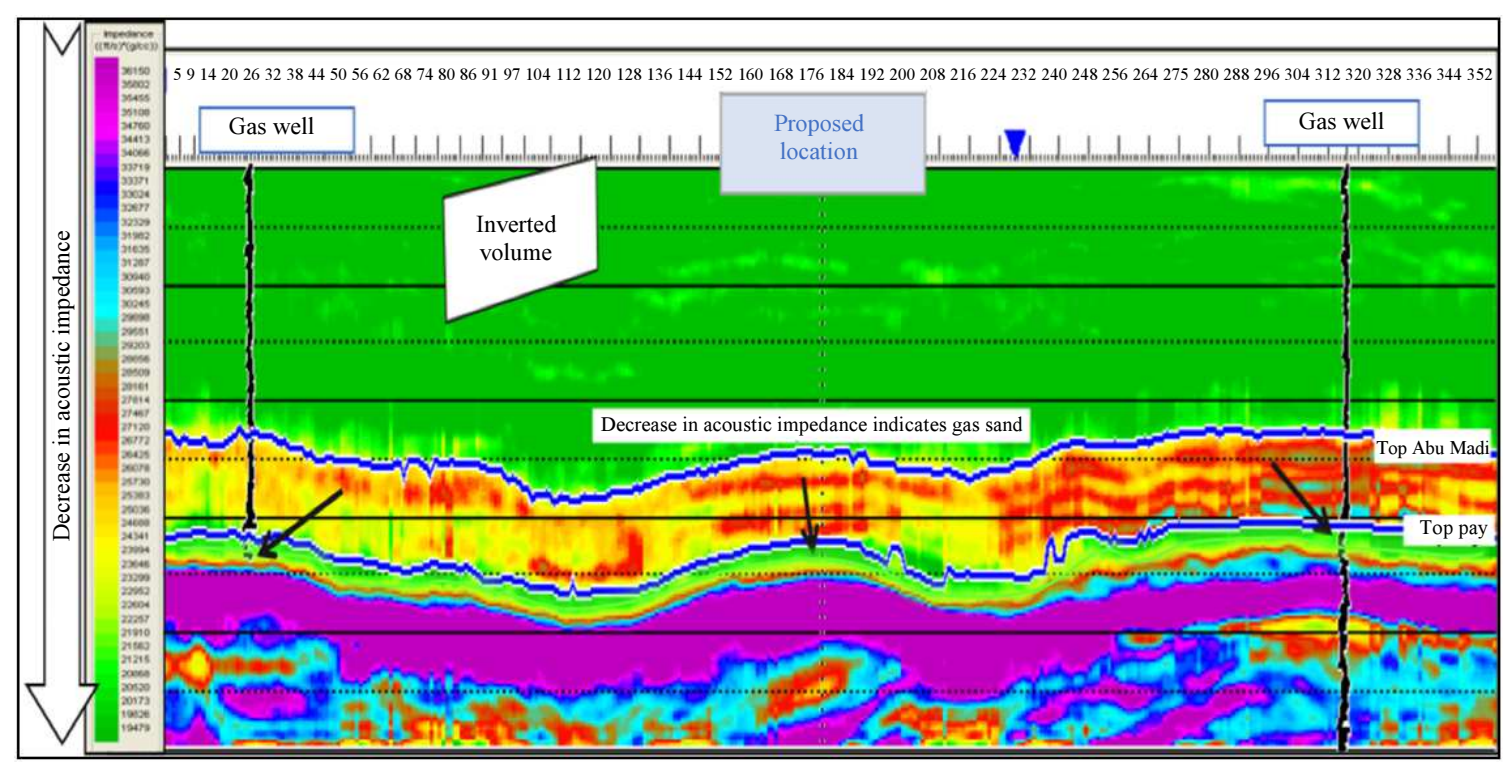

Fig. 22: Arbitrary line between the proposed locations of two gas wells from the inverted cube

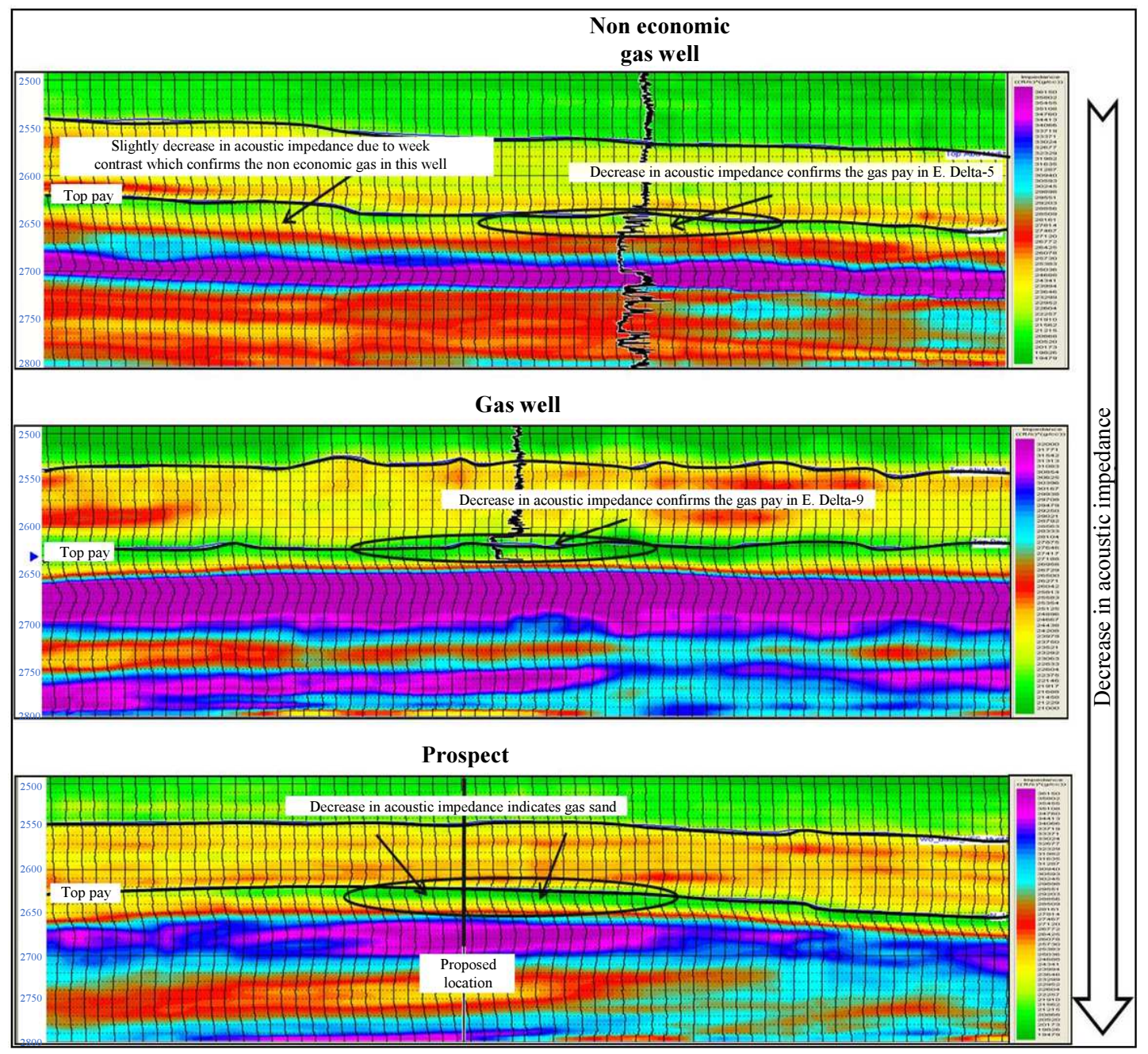

Fig. 23: Vertical sections from the inverted seismic cube 


\section{Conclusion}

The analysis of the CDP gathers on different angles, monitoring the AVO and inversion response, help in validating the prospects and for determining the response of the seismic amplitude variation with the offset, so it is possible to confirm the amplitude anomaly, if it is related to hydrocarbon occurrence or not. The AVO analysis and the pre-stack modeling (sole interface modeling, CDP gather analysis, two-dimension stratigraphic analysis and twodimension elastic wave displaying) allow the interpreter to: (1) Understanding the seismic signature, due to the wave propagation. (2) Defining the reservoir rock physical properties. (3) Integrating seismic, well logs, lab testing and VSP information, to verify the reservoir conditions.

Pre-stack modeling is effective to: (a) Predicting the usefulness of the AVO analysis, before investing time and effort in acquiring seismic. (b) Examining the seismic response, due to lithology's physical properties, such as porosity, fluid content and reservoir and pay thickness. (c) Substituting the pore fluid and modeling the seismic response. (d) Varying the reservoir properties and model the seismic response. (e) Exploring the uniqueness of possible seismic interpretation. (f) Evaluating the exploration potential and recognizing the exploration risk. (g) Processing the synthetic gather, to extract attributes to understand, which may be useful.

\section{Acknowledgement}

The authors would like to extend their sincere appreciation and great thanks to the Egyptian Natural Gas Holding Company (EGAS), Petroceltic-International Plc and El Mansoura Petroleum Company for all their support during the production of this work.

\section{Author's Contributions}

Mohamed Hussein: Has participated in all experiments, coordinated the data-analysis and contributed to the writing of the manuscript.

Ahmed Abu El-Ata and Mohamed El-Behiry: Have designed the research plan, organized the study and coordinated the mouse work and contributed in drafting the article.

\section{Ethics}

The Authors doesn't have any ethical issues or conflict of interest concerning the publication of this work.

\section{References}

Abdel, H.M., 2001. Future hydrocarbon potential in the Nile Delta offshore and onshore. Proceedings of the 1st International Symposium on the Deltas, Mar. 13-19, Cairo, Egypt, pp: 159-174.
Aki, K. and P. Richards, 1980. Quantitative seismology. Theory Methods.

Barclay, F., A. Bruun, J.C. Alfaro, A. Cooke and D. Cooke, 2008. Seismic inversion reading between lines. Schlumberger Oil Field Preview Spring.

Bortfeld, R., 1961. Approximation to the reflection and transmission coefficients of plane longitudinal and transverse waves. Geophysical Prospect., 9: 485-502. DOI: 10.1111/j.1365-2478.1961.tb01670.x

Cardamone, M., B. Ciurlo and V. Noli, 2007. AVO and fluid inversion. ENI.

Castagna, J.P. and H.W. Swan, 1997. Principles of AVO cross-plotting. Lead. Edge, 16: 337-342. DOI: $10.1190 / 1.1437626$

Chopra, S. and R.K. Sharma, 2016. Preconditioning of seismic data prior to impedance inversion, arci's seismic solutions. GS, Calgary- Canada.

EGPC, 1994. Nile Delta and North Sinai: Field discoveries and hydrocarbon potentials (A comprehensive overview). Egyptian General Petroleum Corporation, Cairo, Egypt.

Feng, H. and J.C. Bancroft, 2006. AVO principles, processing and inversion. CREWES Res. Rep., 18: $1-19$.

Hampson, D. and B. Russell, 2006. The old and the new in seismic inversion. Telus Convent. Centre, Calgary.

Hampson, D., B. Russell and B. Bankhead, 2005. Simultaneous inversion of pre-stack seismic data. Ann. Mtg. Abstracts, Soc. Explorat. Geophysicists.

Kamel, H., T. Eita and M. Sarhan, 1998. Nile delta hydrocarbon potentiality, Egypt. Proceedings of the 14th EGPC Exploration and Production Conference. (EPC'98), Cairo, Egypt, pp: 485-503.

Knott, C.G., 1899. Reflection and refraction of elastic waves with seismological applications. Phil. Mag., 48: 64-97. DOI: 10.1080/14786449908621305

Koefoeda, O., 1955. On the effect of poisson ratios of rock strata on the reflection coefficients of plane waves. Geophysical Prospect., 3: 381-387. DOI: $10.1111 /$ j.1365-2478.1955.tb01383.x

Latimer, R.B., R. Davison and P. van Riel, 2000. An interpreter's guide to understanding and working with seismic-derived acoustic impedance data. Lead. Edge, 19: 242-256. DOI: 10.1190/1.1438580

Nandam, C., 2016. Seismic data interpretation and evaluation for hydrocarbon exploration and production. A Practitioner's Guide, Cuttack, Odisha, India.

Nastaran, M. and M. Mokhtari, 2016. Application of post stack and pre stack seismic inversion for prediction of hydrocarbon reservoir in a pers. gulf gas field. Int. J. Environ. Chem. Ecol. Geol. Geophys. Eng., 10: 1-10.

DOI: $10.5281 /$ zenodo.1126059 
Nini, C., F.E. Checchi, A. Blasy and A. Talaat, 2010. Depositional evolution of the plio-pleistocene succession as a key for unraveling the exploration potential of the post-musician play in the Central Nile Delta. MOC.

Ostrander, W.J., 1984. Plane-wave reflection coefficients for gas sands at non normal angles of incidence. Geophys. 49: 1637-1648. DOI: 10.1190/1.1441571

Ramos, A.C.B., A.S. Oliveira and M. Tygel, 1999. The impact of true amplitude DMO on amplitude versus offset. 69th Ann. Internet Mtg. Soc. Expl. Geophys.

Rizzini, A., F. Vezzani, V. Coccocetta and G. Milad, 1978. Stratigraphy and sedimentation of neogenequaternary section in the Nile Delta area. Marine Geol., 27: 327-348.

DOI: $10.1016 / 0025-3227(78) 90038-5$

Ross, D. and E. Uchupi, 1977. Structure and sedimentary history of northeastern mediterranean Sea-Nile cone area. AAPG. Bull., 61: 872-902.

Russell, B., 2014. Seismic reservoir characterization and pre-stack inversion in resource shale plays. Calgary, Canada, Posted.
Rutherford, S.R. and R.H. Williams, 1989. Amplitude versus offset variations in gas sands. Geophysics, 54: 680-688. DOI: 10.1190/1.1442696

Said, R., 1962. The Geology of Egypt. 1st Edn., Elsevier, New York.

Shuey, R.T., 1985. A simplification of the zoeppritz equations. Geophysics, 50: 609-614. DOI: $10.1190 / 1.1441936$

Smith, G.C. and P.M. Gidlow, 1987. Weighted stacking for rock property estimation and detection of gas. Geophys. Prosp., 35: 993-1014. DOI: $10.1111 / \mathrm{j} .1365-2478.1987 . t b 00856 . x$

Verm, R. and F. Hilterman, 1994. Lithology color-coded seismic sections: The calibration of AVO crossplotting to rock properties. Lead. Edge, 14: 847-853. DOI: $10.1190 / 1.1437170$

Yilmaz, O., 2001. Seismic Data Processing. 1st Edn., Society of Exploration Geophysicists, Tulsa, ISBN-10: 0931830419 , pp: 526.

Zoeppritz, K., 1919. Erdbebenwellen VIIIB, on the reflection and propagation of seismic waves. Göttinger Nachrichten, I. 